Portland State University

PDXScholar

\title{
Assessment of Multi-Stressors on Compositional Turnover of Diatom, Invertebrate and Fish Assemblages Along an Urban Gradient in Pacific Northwest Streams (USA)
}

Ian Waite

U.S. Geological Survey, Portland, OR

Yangdong Pan

Portland State University, pany@pdx.edu

Patrick M. Edwards

Portland State University, patrick.edwards@pdx.edu

Follow this and additional works at: https://pdxscholar.library.pdx.edu/esm_fac

Part of the Environmental Indicators and Impact Assessment Commons Let us know how access to this document benefits you.

\section{Citation Details}

Waite, I. R., Pan, Y., \& Edwards, P. M. (2020). Assessment of multi-stressors on compositional turnover of diatom, invertebrate and fish assemblages along an urban gradient in Pacific Northwest streams (USA). Ecological Indicators, 112, 106047.

This Article is brought to you for free and open access. It has been accepted for inclusion in Environmental Science and Management Faculty Publications and Presentations by an authorized administrator of PDXScholar. Please contact us if we can make this document more accessible: pdxscholar@pdx.edu. 


\title{
Assessment of multi-stressors on compositional turnover of diatom, invertebrate and fish assemblages along an urban gradient in Pacific Northwest streams (USA)
}

\author{
Ian R. Waite ${ }^{\mathrm{a}, *}$, Yangdong Pan ${ }^{\mathrm{b}}$, Patrick M. Edwards ${ }^{\mathrm{b}}$ \\ ${ }^{a}$ U.S. Geological Survey, 2130 SW 5th Ave., Portland, OR 97201, United States \\ ${ }^{\mathrm{b}}$ Environmental Science and Management, Portland State University, United States
}

A R T I C L E I N F O

\section{Keywords:}

Gradient forest

Modeling

Multiple stressors

Contaminants

Bioassessment

Drought

\begin{abstract}
A B S T R A C T
This study is part of the regional stream-quality assessment (RSQA) conducted by the U.S. Geological Survey (USGS) National Water Quality Assessment (NAWQA) project. The purpose of this study is to examine small streams along land-use and stressor gradients at the regional scale and to evaluate the relative importance of instream stressors on diatom, macroinvertebrate, and fish assemblages. In 2015, the RSQA project assessed stream quality in 82 wadeable streams that were selected along an urban land-use gradient in the Pacific Northwest Region (PNW) of the United States. This study evaluates the effects of four major categories of measured instream stressors - flow (i.e. alteration), water quality, habitat, and contaminants (in water and sediment) - on stream biota. We used gradient forest (GF) models to evaluate taxon specific responses to the various stressors for the three biotic assemblages. Results for diatom, invertebrate and fish assemblages showed that several environmental variables including substrate size, dissolved oxygen, and two or more different contaminants were selected in each of the GF models. In general, all three assemblages were negatively associated with any contaminant measures above zero, except the more tolerant taxa in each assemblage, which responded positively to contaminants. Total nitrogen (TN) and total phosphorus (TP) were important in both the diatom and invertebrate GF models but not in the fish models, which were related to temperature and stream flow. TP and TN were the top two variables for diatom GF models and various taxa responded at a range of nutrient concentrations; however, some taxa responded at low concentrations, for example around 0.02 for TP and $0.5 \mathrm{mg} / \mathrm{L}$ for TN. In general, the three biotic assemblages responded to multiple stressors following general patterns of known sensitive versus tolerant taxa for each of the biotic groups studied, yet the GF models allow us to explore taxon specific responses. For example, most of the sensitive Ephemeroptera, Plecoptera, Trichoptera invertebrate taxa (EPT) responded negatively when any contaminant increased above zero; yet some taxa such as the tolerant Trichoptera Cheumatopsyche responded positively to contaminants and many of the other stressors. The findings of this study demonstrate the value of using multiple assemblages to monitoring stressor gradients associated with urban stream systems and the importance of evaluating the responses of individual taxa to stressors.
\end{abstract}

\section{Introduction}

The effect of urban land use on aquatic ecosystems has been intensively studied, resulting in researchers coining the term "Urban Stream Syndrome," which refers to the common effects of urbanization on streams around the world (Walsh et al., 2005). Included in these syndromes are changes to hydrology (i.e., increased flashiness), modification of habitat and channel morphology, reduction in general water quality (i.e., temperature, dissolved oxygen), and increases in nutrients and contaminants. Currently, there are increased efforts to assess the effects of multiple stressors in aquatic ecosystems and several common patterns are emerging (Dahm et al., 2013; Feld, 2013; Mondy et al., 2016; Waite et al., 2019). In both urban and agriculture-influenced watersheds, streams commonly exhibit disturbance due to increased temperature and nutrients, lower dissolved oxygen and increased sediments (U.S. Environmental Protection Agency, 2006; Carlisle et al., 2013). However, when compared to agriculture stream systems, urban streams tend to have more impacts due to flow alteration (e.g.,

\footnotetext{
* Corresponding author.

E-mail address: iwaite@usgs.gov (I.R. Waite).
} 


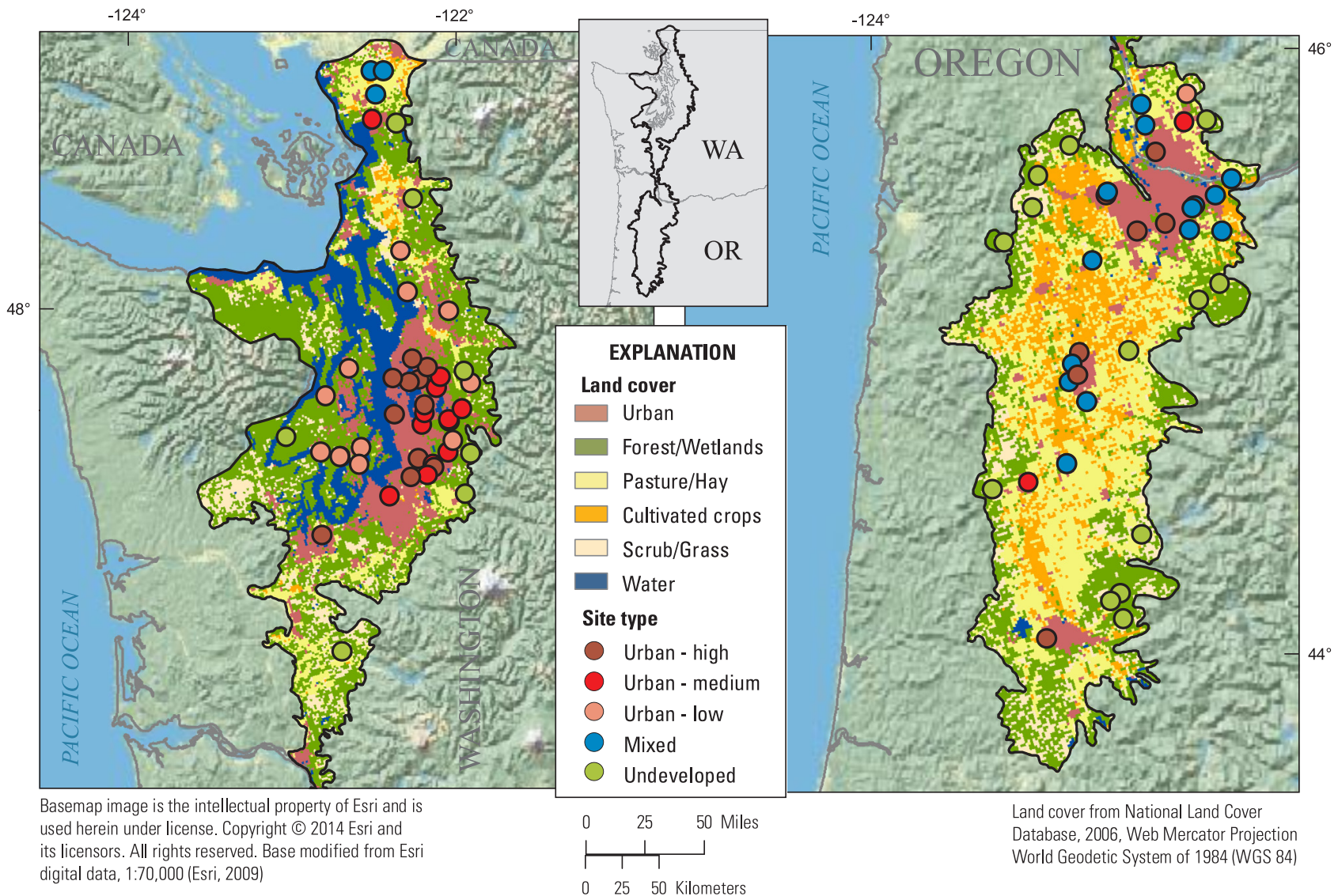

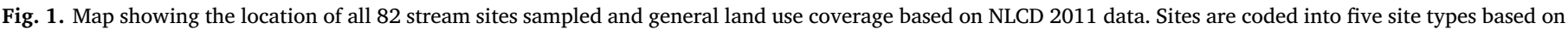
amount of urban land use in watershed. For complete list of stream sites, location and general basin characteristics, see Supplemental File, Table S1.

increased flashiness) and experience a wider range of contaminants including insecticides, industrial compounds (i.e., PAH's, PCB's, metals) and sediment-bound contaminants (Brown et al., 2009; Cuffney et al., 2010; Nowell et al., 2013; Stehle et al., 2019; Waite et al., 2019).

Previous research on multiple stressors in streams have used aggregates of biotic assemblages (i.e., metrics and indices) which may generalize stressor relationships across the assemblages (Villeneuve et al., 2015; Mondy et al., 2016; Gieswein et al., 2017; Waite et al., 2019). These biotic metrics work well for overall bioassessments; however, they may miss important individual taxon or species response to stressors and thus may not be as protective of sensitive species. Moreover, biotic metrics do not allow the evaluation of species-specific thresholds (Wagenhoff et al., 2017; Waite and Van Metre, 2017). Furthermore, it is well documented that the biotic responses to stressors can be different across diatoms, macroinvertebrates (invertebrates), and fish assemblages and thus different assemblages may provide different information about relevant stressors (Schinegger et al., 2016; Graeber et al., 2017; Kuzmanovic et al., 2016; Waite et al., 2019).

A new modeling technique called "gradient forest" (GF) has been developed that creates random forest models for each individual taxon in the sampled assemblage. This allows for the assessment of potential species-specific thresholds and, as a whole, provides a measure of taxonomic compositional turnover across environmental gradients (Ellis et al., 2012; Pitcher et al., 2012; Wagenhoff et al., 2017). Random forest is a member of the tree-based family of models, which includes Boosted Regression Trees (BRT) and Classification and Regression trees (CART), that all have the ability to describe nonlinear response forms, incorporate multiple predictors and handle potential interactions directly (De'ath, 2007; Elith et al., 2008). GF models are better-suited than traditional multi-metrics for investigating the relationship between biotic assemblages and environmental stressors because they allow for the evaluation of both specific and aggregate biotic-stressor responses to identify potential individual thresholds and assemblage turnover across these disturbance gradients.

In a study of nine urban metropolitan areas in the United States, Coles et al. (2012) found there was no single stressor type that was universally important; however, altered hydrology, changes in stream channels, and increases in contaminants were important in many of the study regions. Because of high temporal and spatial variability of stream contaminants, as well as the high cost of analyzing samples, contaminant sampling can be challenging, thus contaminants are often not included in many multi-stressor studies (Mondy et al., 2016; Ponsati et al., 2016; Schafer et al., 2016; Waite et al., 2019). In this study, multiple weekly samples and media (water and sediment) were analyzed with an expanded list of parent and degradate chemical analytes compared to most previous research. In addition, many of the previous studies focused on the effects of landscape alteration (i.e., GIS based urban land use, roads, point source, etc.) whereas we focus on linking the direct measurement of instream stressors to their effects on the biota, thus avoiding a more general assessment of land use as a stressor.

This study represents the third of five regional stream-quality assessment (RSQA) studies conducted by the U.S. Geological Survey (USGS) National Water Quality Assessment (NAWQA) project. The overall purpose of the RSQA studies is to examine small streams along land-use and stressor gradients at the regional scale and to evaluate the relative importance of different measured instream stressors on diatom, invertebrate, and fish assemblages. In 2015, the project assessed stream quality in 82 wadeable streams along an urban land use gradient in the Pacific Northwest Region (PNW) of the United States. The objectives of this study were to evaluate multiple stressors for the three biotic assemblages representing a typical stream food-web across an urban disturbance gradient and determine both assemblage-level and species- 
or taxon-specific responses to various instream stressors. This study is unique in that we have four major categories of instream stressors (flow i.e. alteration; water quality; habitat; and contaminants) assessed across a large urban regional study area, the assessment of three diverse biotic assemblages and, through the use of gradient forest models, the ability to evaluate taxon specific responses to these various stressors. In this study, we expect that the diatom, macroinvertebrate and fish assemblages will have different responses to the urbanization gradient and that they will provide different information about specific taxon-specific responses to urban stressors. For each of the biotic groups studied, we also expect that there will be distinct taxa that will respond to these stressors following known patterns previously observed of sensitive versus tolerant taxa.

\section{Methods}

\subsection{Study area description}

The PNW study area encompasses watersheds in the Willamette Valley and Puget Lowland Level III Ecoregions (Omernik, 1995) in the States of Oregon and Washington (Fig. 1) (Sheibley et al., 2017). The Puget Lowland Ecoregion covers an area of $18,000 \mathrm{~km}^{2}$ (Sorenson, 2012) in western Washington State. This ecoregion is bounded by the Coast Range Ecoregion to the west and Cascade Range Ecoregion to the east and follows the Interstate 5 corridor from the Canadian border south to the northern border of the Willamette Valley Ecoregion, near Portland, Oregon. Elevations within the ecoregion range from sea level to $460 \mathrm{~m}$, with an average about $150 \mathrm{~m}$ (DellaSala et al., 2001). Climate in the Puget Lowland Ecoregion is a mild, maritime climate (U.S. Environmental Protection Agency, 1999). For 1981-2010, the average minimum temperature ranged from 5 to $7^{\circ}$ Celsius $\left({ }^{\circ} \mathrm{C}\right)$, with the average maximum from 13 to $17{ }^{\circ} \mathrm{C}$ (National Climatic Data Center, 2010). Average annual precipitation in the Puget Lowland Ecoregion ranged from 48 to $167 \mathrm{~cm}$ during the same period. Prior to European settlement, the primary land cover in the Puget Lowland Ecoregion was coniferous forests dominated by Douglas-fir (Sorenson, 2012).

Seattle is the largest city in the ecoregion with 608,660 people (U.S. Census Bureau, 2010), and the population of the central Puget Sound region is nearly 4 million people (Puget Sound Regional Council, 2016). From 2015 to 2016, the central Puget Sound had the largest 1-year increase in population this century with an increase of about 87,000 people (Puget Sound Regional Council, 2016). Land-cover change from 1973 to 2000 resulted in a large decrease in forested land cover (about 10 percent) and a large increase in developed land cover (about seven percent), with agriculture remaining at about the same level (decrease of 0.6 percent) (Sorenson, 2012). In general spatial terms, the center of the Puget Lowland Ecoregion is dominated by developed land cover (Seattle metropolitan area), with agriculture mainly on river floodplains to the north and south, and the remaining outer regions dominated by forests (Fig. 1).

The Willamette Valley Ecoregion covers about 14,360 km² (Wilson and Sorenson, 2012). The alluvial Willamette Valley extends north to south between the Coast Range Ecoregion to the west and Cascades Ecoregion to the east (Fig. 1). Most of the ecoregion is in Oregon, but the northern extent reaches into southwestern Washington State where the Lewis and Columbia Rivers converge. The Willamette Valley Ecoregion shares its northern border with the Puget Lowland Ecoregion and the southern border with the Klamath Mountains Ecoregion. The topography in the ecoregion is relatively flat, ranging from sea level to $122 \mathrm{~m}$ (Wilson and Sorenson, 2012). Climate in the Willamette Valley Ecoregion is temperate Mediterranean (U.S. Environmental Protection Agency, 1999), average annual minimum temperatures for 1981-2010 ranged from 4 to $8{ }^{\circ} \mathrm{C}$, with an average maximum from 13 to $18{ }^{\circ} \mathrm{C}$ (National Climatic Data Center, 2010). Average annual precipitation in the Willamette Valley Ecoregion ranged from 91 to $205 \mathrm{~cm}$ during the same period.
The flat terrain and fertile soils, mild wet winters, and dry summers, make the Willamette Valley the most important agricultural region in the State (U.S. Environmental Protection Agency, 1999). The largest city in the ecoregion is Portland, with a population of 583,776 in 2010 (U.S. Census Bureau, 2010), and the total population in the Willamette Valley is about 2.3 million (Oregon Department of Fish and Wildlife, 2006). This area is a major producer of agricultural and forest products, including grass seed, fruit, nuts, grains, and livestock (Wilson and Sorenson, 2012). Like the Puget Lowland Ecoregion to the north, the greatest decrease in land-cover type in the Willamette Valley Ecoregion between 1973 and 2000 was forest (about four percent) and greatest increase in land-cover type was developed land (about three percent); agricultural land cover decreased by about two percent during this same period (Wilson and Sorenson, 2012).

\subsection{Study design}

The study utilized a gradient approach to select stream sites that represented a range of urban development across the region, subdivided for design purposes into three urban tiers based on intensity of urban land use. Watersheds that lie predominantly or entirely within protected areas (such as parks and wildlife refuges) or are predominantly forested (with limited or no urban development), were considered reference conditions. At the other end of the continuum are watersheds in the major urban centers of Seattle and Portland that are subject to highintensity urban development. The design of this study allowed us to assess the impacts from multiple stressors associated with urbanization in the PNW study area by targeting streams that represent a regional gradient from low- to high-intensity urban development. Eighty-seven stream sites were sampled in the gradient approach, 71 urban tier sites, 11 reference and five agricultural sites (Fig. 1) (Sheibley et al., 2017); however, for this study, we removed the five sites primarily influenced by agricultural land use to focus on the effects of urbanization. Sites ranged in watershed size from 5 to $205 \mathrm{~km}^{2}$, with the 5 and 95 quartiles ranging from 7 to $103 \mathrm{~km}^{2}$, respectively (Supplemental Information Table S1 Site List).

\subsection{Data collection and processing}

Stream sites were sampled from April-June 2015 and sampling frequency and timing varied by site type. Weekly water sampling was collected during a water-quality "index period" that spanned 10 weeks for most sites. This index period was reduced to four weeks at all reference sites and at a few of the low urban land-use sites to reduce sampling costs, since pesticides are least likely to occur at these sites. For comparability, all water quality data used in analyses in this paper focuses only on the last four weeks of sampling completed across all sites. A one-time ecological survey of stream habitat, algae (diatoms), benthic macroinvertebrates, and fish was conducted at all sites over a 2week period, beginning the final week of the 10 -week water-quality index period and extending through the week that followed (weeks 10 and 11). Streambed sediment was collected during the ecological survey for analysis of sediment chemistry and laboratory toxicity testing.

Weekly discrete samples of water chemistry were collected at all sites. Discrete samples may not accurately reflect the exposure of biota to short-term "spikes" in high chemical concentrations that are potentially acutely toxic. Therefore, to complement weekly collection of discrete stream samples, polar organic chemical integrative samplers (POCIS), and continuous water-quality data also were used in the study. Passive POCIS samplers were used to collect time-weighted average concentrations of polar organic compounds at 75 of the 87 sites. Weekly water-quality samples were collected for major ions, nutrients, pesticides, glyphosate, and suspended-sediment concentration. Unless otherwise noted, chemical analyses were conducted at the USGS National Water Quality Laboratory (NWQL). Briefly, water and POCIS 
extracts both were analyzed for 225 dissolved pesticides and degradates (except glyphosate) using direct aqueous injection liquid chromatography tandem mass spectrometry (DAI LC-MS/MS) (Sandstrom et al., 2015). Glyphosate was analyzed separately at the USGS Texas Water Science Center in Austin, Texas, by enzyme linked immunosorbent assay (ELISA) (Mahler et al., 2017). Detailed explanation of water sampling procedures and protocols are presented in Sheibley et al. (2017). Field properties of specific conductance, $\mathrm{pH}$, dissolved oxygen, and water temperature were measured at the time of sampling with a field-calibrated multi-parameter sonde.

\subsection{Continuous water data collection}

At stream sites where continuous stream gages did not exist (52 of 82 sites; SI Table 1), digital water-level loggers were deployed that recorded water temperature and water level (stage). Internally logging digital devices were deployed prior to April 15, 2015, the beginning of the data collection period, and remained deployed until September-October 2015. Deployment included the installation of two loggers per site-one to measure water level (water column) and one to measure barometric pressure (air). Each water logger was mounted at a depth where it would remain continually submerged, yet be readily accessed if needed. The barometric pressure logger typically was fixed to a nearby tree or bridge infrastructure. When possible, instream loggers were deployed about $15 \mathrm{~cm}$ above the streambed, out of direct sunlight, and attached to rebar anchored in the streambed or to stable parts of stream gage infrastructure or bridge piers if these structures were present at the site.

\subsection{Ecological data collection}

Diatom, invertebrate, and fish samples were collected and habitat was assessed along a 150-m ecological-assessment reach, according to the methods described in Moulton et al. (2002). All field data were recorded on electronic forms using hand-held tablet computers. Raw field data collected from the fish and habitat surveys, and field records for the algal and invertebrate samples destined for laboratory analysis were loaded in the USGS BioData biological database (https://aquatic. biodata.usgs.gov).

Diatom and invertebrate assemblages were sampled using standard USGS richest-targeted habitat (RTH) protocols (Moulton et al., 2002; Hambrook and Canova, 2007). RTH samples are intended to represent the habitat features (usually a riffle) having the greatest diversity of organisms within a given stream reach. The benthic algae were scraped from natural substrates (for example, flat rocks) to obtain a targeted area of $150 \mathrm{~cm}^{2}$. The substrate was scraped with a brush in a defined area and flushed into a $500-\mathrm{mL}$ bottle with water from that stream. Typically, 11 subsamples of equal size were combined in a single composited algal sample to represent the site. The sample was preserved with buffered formalin at a concentration of about five percent and sent to the University of Colorado for algal taxa identification and enumeration (Spaulding et al., 2010).

Invertebrate samples were collected from the RTH (typically a riffle with gravel to cobble substrate), using a modified Surber sampler with $500-\mu \mathrm{m}$ mesh net that samples a $0.25 \mathrm{~m}^{2}$ area of substrate (Moulton et al., 2002). The total invertebrate sample area was targeted at $1.25 \mathrm{~m}^{2}$, the sum of a composite of five modified Surber samples. The large organic and inorganic debris was removed, and then the remaining organic sample with invertebrates was transferred to a $1-\mathrm{L}$ bottle and preserved with 10-percent buffered formalin. Large or rare invertebrates, such as crayfish and larger mollusks, were photographed and released in accordance with collection permit procedures. Invertebrate samples were shipped to NWQL for identification and enumeration of taxa (generally either genus or species).

A representative fish-community sample was collected at each site using backpack-mounted electrofishing units following a two-pass procedure (Moulton et al., 2002). Fish generally were identified to species, counted in the field, and then released within the collection reach. In the few cases where a fish could not be positively identified in the field, an individual fish was preserved for later identification.

The physical habitat of the reach was characterized following USGS protocols (Fitzpatrick et al., 1998). Reach lengths for this study were $150 \mathrm{~m}$ at each site. Qualitative and quantitative measurements were collected at 11 primary and 10 secondary transects. Depending on the transect type, these measurements included, but were not limited to, depth, wetted width, substrate particle size, canopy cover, macrophyte coverage, bank height, presence of bars and islands, and instream fish habitat. Geomorphic channel units such as pools, riffles, and runs were characterized by size and frequency.

Detailed information is provided in Sheibley et al. (2017) on all laboratory procedures for all water sample analyses and ecological sample processing as well as information on quality assurance and quality control procedures. National RSQA team members reviewed the water-quality and sediment-quality results received from the laboratory. The water-quality data reviews included identification and review of extremes in the data (outliers), inconsistencies or unexpected results in the data, and major differences between environmental samples and replicates, detected values in blanks, and analyte recoveries in spike samples.

\subsection{Data analysis}

GF is a novel statistical approach that has advantages over traditional tree-based learning techniques (Ellis et al., 2012). GF creates multiple random forest models for each species, then provides graphs on species-stressor responses and overall community turnover response. GF was applied to the data for the three assemblages to quantify the shape and magnitude of species compositional turnover across the urban stressor gradients. GF models were implemented separately for diatom, invertebrate and fish assemblages in the statistical program $\mathrm{R}$ (version 3.5.0). To meet statistical requirements, rare taxa were removed separately for each assemblage by dropping those taxa that did not occur at least $10 \%$ of the sites. Taxon relative abundances were logtransformed and models run with 105 individual environmental variables within four stressor categories; flow, water quality, habitat and contaminants (variable definitions of final model variables are provided in SI Table 2). Predictors do not need to be transformed for regression tree models.

In GF models, the random forests models provide three measures that are used to investigate biotic response: the model goodness-of-fit measure $\mathrm{R}^{2}$ for each taxon, the accuracy importance for each predictor within the forest, and the raw importance for each predictor at each split value in a particular tree. The turnover functions on the instream stressors (predictors) are obtained by distributing the $\mathrm{R}^{2}$ values from all taxa among the predictors in proportion to their accuracy importance and along the predictor gradient according to the density of the raw importances (Ellis et al., 2012). This is done by finding for each tree all splits involved with a predictor and its associated impurity importances (i.e., reduction of deviance due to the split) then standardized by density and normalized to sum to $\mathrm{R}^{2}$ for that taxon (Figs. 2, 5, 8). RF models consisting of 500 regression trees for each taxon were run using the $\mathrm{R}$ package extendedForest (based on package randomForest).

Each regression tree is fit to a bootstrap sample of the observations and partitioning of the data is performed by the best split (minimizing error variance) by testing a random subsample of the predictors (Ellis et al., 2012; Wagenhoff et al., 2017). Each split is associated with an importance value reflecting the degree of change in abundance. The RF model predictions are averages of the predictions of each tree and the goodness-of-fit measure $\mathrm{R}^{2}$ is the proportion of the variance explained by the RF model derived through cross-validation. The package extendedForest calculates an improved, more robust measure of predictor importance within each RF by taking into account correlation between 

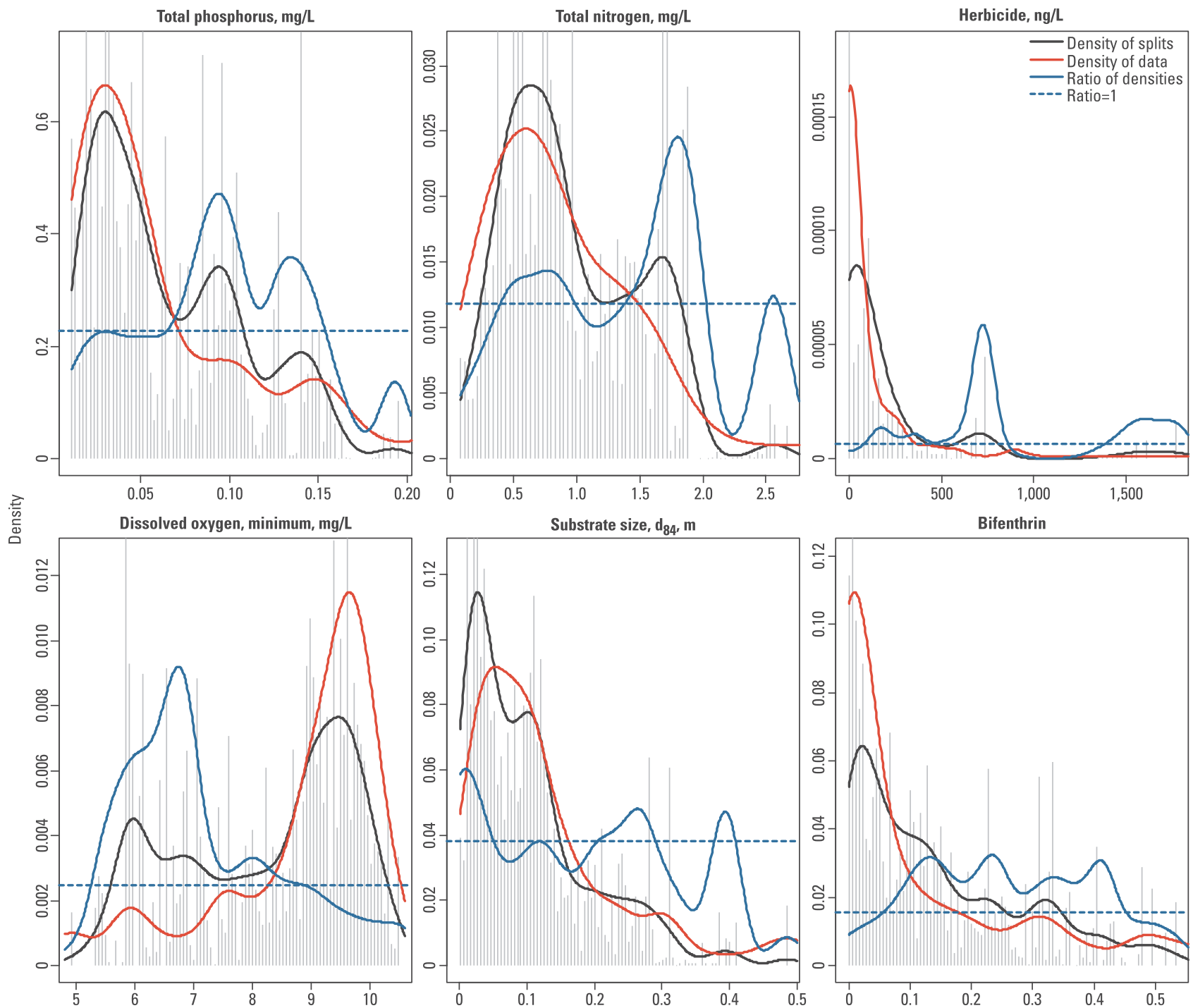

Fig. 2. Split density plots for diatom assemblages from gradient forest models from streams in the Pacific Northwest regional study ( $\mathrm{n}=82$ ). Split density showing the raw split importance computed from split point density weighted by importance (black line), the binned raw split importance density (narrow gray bars), the density function of the observed predictor values (red line), and the estimated importance function or compositional turnover rate (blue line) is computed as the ratio of split and data density (black/red lines). The raw importances are normalized so that the area under the blue curve is equal to the $\mathrm{R}^{2}$ for all species for that environmental variable (Ellis et al., 2012). Ratios $>1$ (dashed horizontal line) of the importance function indicate that compositional rate of change is relatively larger in that stressor range than elsewhere in the stressor gradient. Thresholds are visually identified in those areas where the blue line is above the dashed line, yet considering the full range of the stressor. For variable definitions and units, see Supplemental File, Table S2.

predictors (Ellis et al., 2012). The default correlation threshold of 0.5 as well as other default settings were used. The $\mathrm{R}$ package gradientForest uses information from all RF models with $\mathrm{R}^{2}>0$ from extendedForest to calculate the final model output. Like all regression tree techniques, predictors are ranked by taking a weighted average of the conditional importances (species-specific) using $\mathrm{R}^{2}$ values of the RF models. Species turnover functions are computed using information on the predictor splits and associated importance within each tree by accumulating the split importance values across the stressor gradients. Field survey data is rarely uniformly distributed across the stressor gradients, and as a result, split density is biased toward values where sampling is more intense; therefore, GF standardizes split density by the density of the observed values across each stressor. For this paper, we were most interested in the variable importances across all taxa within each assemblage (Density split plots) and the species-specific cumulative importance curves for the final most important stressors (6-9) that we could interpret for each assemblage.

We also evaluated the relationship between environmental variables and the stream biota with ordinations and vector-fitting analysis. Ordinations are used to plot biotic assemblages as a map where each sample assemblage is displayed as a single point along scaled axes. In the ordination, points that are close together indicate biotic assemblages that are more similar, whereas points that are far apart on the ordination represent biotic assemblages that are relatively different. Non-Metric Multidimensional Scaling (NMDS) based on Bray-Curtis dissimilarities (Legendre and Legendre, 1998, McCune and Grace, 2002) were created for each biotic group using relative abundance data for the taxa selected in the GF models.

We used vector-fitting analysis to overlay the environmental variables selected in the GF models onto the ordinations of each biotic group. Vector-fitting analysis was conducted using a vector fitting function called envfits (Oksanen, 2011) to overlay vectors on the ordination. The vectors show the direction and magnitude of the environmental variables in relation to the points on the ordination. Vectors were statistically evaluated using a permutation-based test (Oksanen, 2011). All analyses were completed using R statistical 


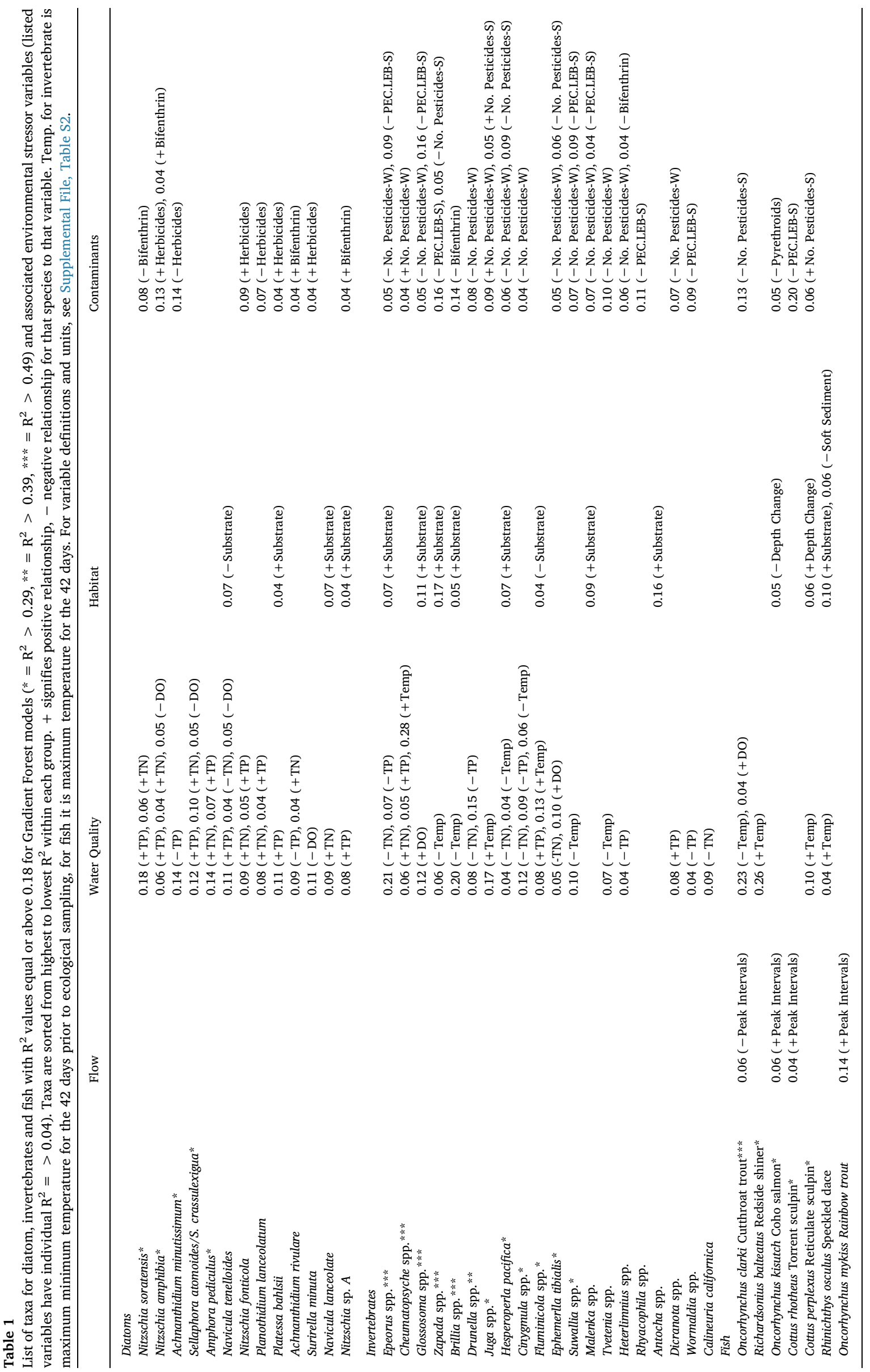


software (Version 3.5.0; R Core Team, 2017).

\section{Results}

\subsection{Diatom}

There was a total of 374 diatom taxa from all sites, Cocconeis placentula was the most common species occurring at 79 of the 80 sites where diatom data was collected (two sites did not have enough diatoms to allow laboratory species identification). Five other taxa occurred at 70 or more sites (Achnanthidium minutissimum, Planothidium lanceolatum, A. rivulare, Gomphonema kobayasii, and Rhoicosphenia abbreviata). Once rare taxa were removed (those taxa occurring at fewer than nine sites), there were 108 taxa and for 37 of these diatom taxa we were able to produce a positive GF model (positive $\mathrm{R}^{2}$ ). Table 1 lists those taxa by biotic group with model $\mathrm{R}^{2}$ greater than 0.18 and the final environmental variables in the GF models associated with each of these taxa that had $\mathrm{R}^{2}$ values greater than 0.04 (selected variable definitions in Supplemental file SI Table 2). This combination reduces the number of taxa-environmental variable relationships; however, this keeps the strongest responses and facilitated interpretation. We retained six of the 105 environmental stressor variables entered into diatom model development in the final GF models (Figs. 2 and 3). There were 13 diatom taxa with GF model $\mathrm{R}^{2}$ greater than 0.18 , all except one of the taxa had one or both of the nutrients (Total nitrogen: TN; Total phosphorus: TP) as important stressor variables in the individual models (Table 1). Six diatom taxa had positive responses to both nutrients, two taxa had a negative response to one nutrient but positive to the other and four taxa had a significant response to only one nutrient - three positive, one negative.

Many of the taxa that had positive responses to TP and TN also showed a positive response to one of the contaminants, either bifenthrin or herbicides (Table 1). However, there were two taxa that were positive for both nutrients and then had a negative response to one of the contaminants. Overall, there were nine diatom taxa that showed a response to one of the contaminants (herbicides or bifenthrin), while four taxa responded to substrate size $\left(\mathrm{d}_{50}\right)$ and four to dissolved oxygen minimum (DO). Of the four taxa that had either DO or substrate as important variables, all had negative responses to increasing DO concentration while three had positive and one negative response for increasing substrate size.

As expected, the top two variables for the diatom models were TP and TN, which showed approximate response thresholds across all taxa at 0.02 and $0.5 \mathrm{mg} / \mathrm{L}$ for TP and TN, respectively (Figs. 2 and 3). The split density plots also show that diatom taxa begin responding to pesticide concentrations and substrate size almost immediately and Table 1 shows the strength and direction of each taxon's response to herbicides and to substrate size. Figs. 2 and 3 show that most diatom taxa respond to DO minimum values beginning in the range between 6 and $7 \mathrm{mg} / \mathrm{L}$. Cumulative split importance curves show all taxa with significant GF models and show the specific taxa that are responding in the range highlighted by the blue curves in the split density plots (Fig. 2); however, only the top 8 taxa for each stressor variable are labeled and given individual colors in these cumulative plots (Figs. 3, 6, and 9). The cumulative importance curves show the response shape for individual taxa and where the major thresholds occur, however, they do not provide the response direction for each taxon. Therefore, we included the response direction for each taxon in Table 1 as indicated by the - or + next to the stressor variable name. For example, Nitzschia soratensis shows a strong response to bifenthrin in sediment starting almost immediately, while $N$. amphibia starts responding after a value of 0.1 (Fig. 3), however, $N$. soratensis shows a negative response to bifenthrin while $N$. amphibia shows a positive response (Table 1). A similar pattern occurs for the herbicide stressor variable, Achnanthidium minutissimum shows a negative response starting at low concentrations, while $N$. fonticola shows a positive response starting at slightly higher
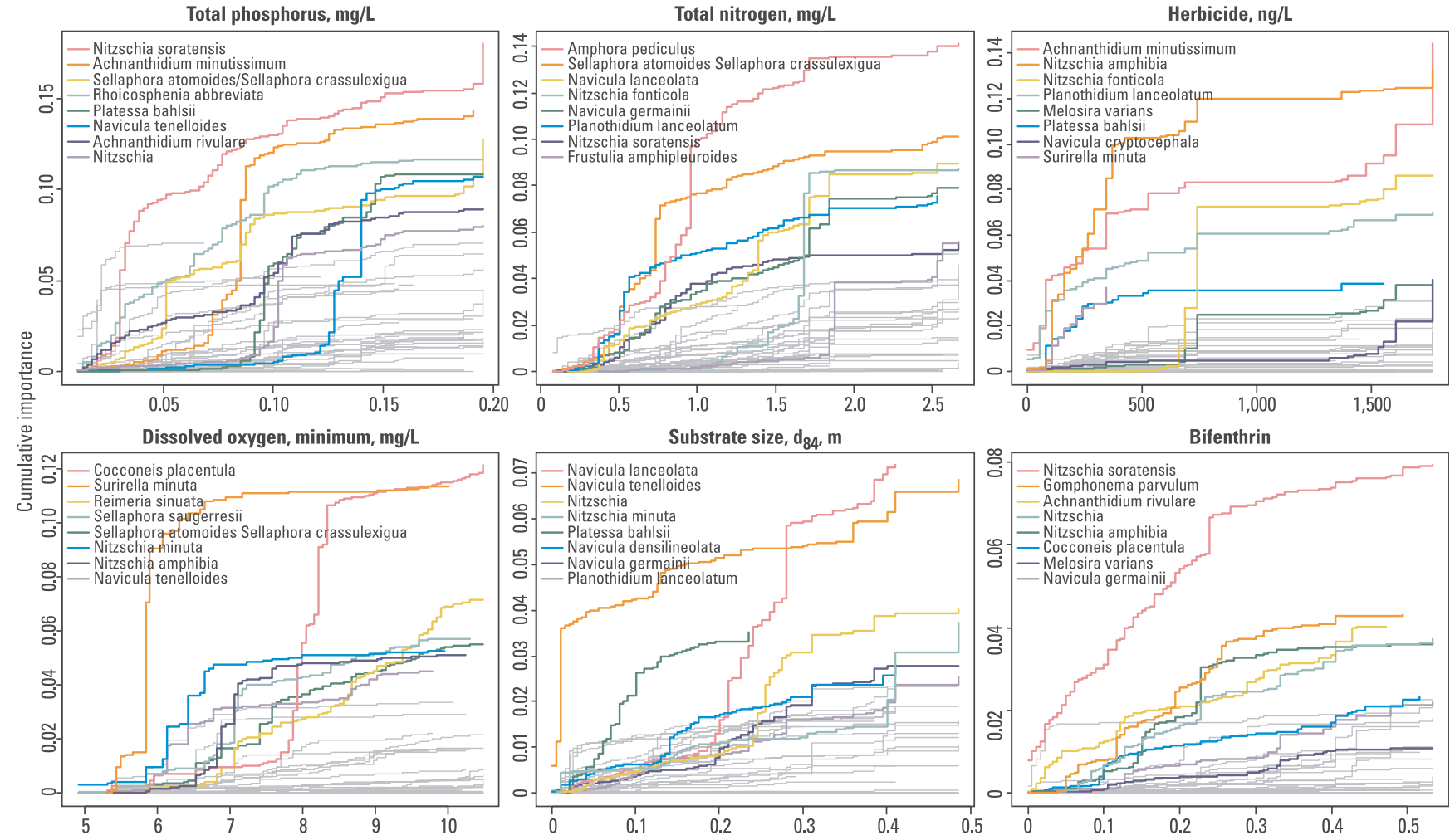

Fig. 3. Cumulative split importance curves for diatom taxa scaled by their respective $\mathrm{R}^{2}$ from gradient forest models from streams in the Pacific Northwest regional study $(n=80)$. Only the top eight most important taxa are labeled. Note: these are cumulative plots, the directionality of the taxa responses cannot be seen in these plots, see Table 1 for response direction. For variable definitions and units, see Supplemental File, Table S2. 

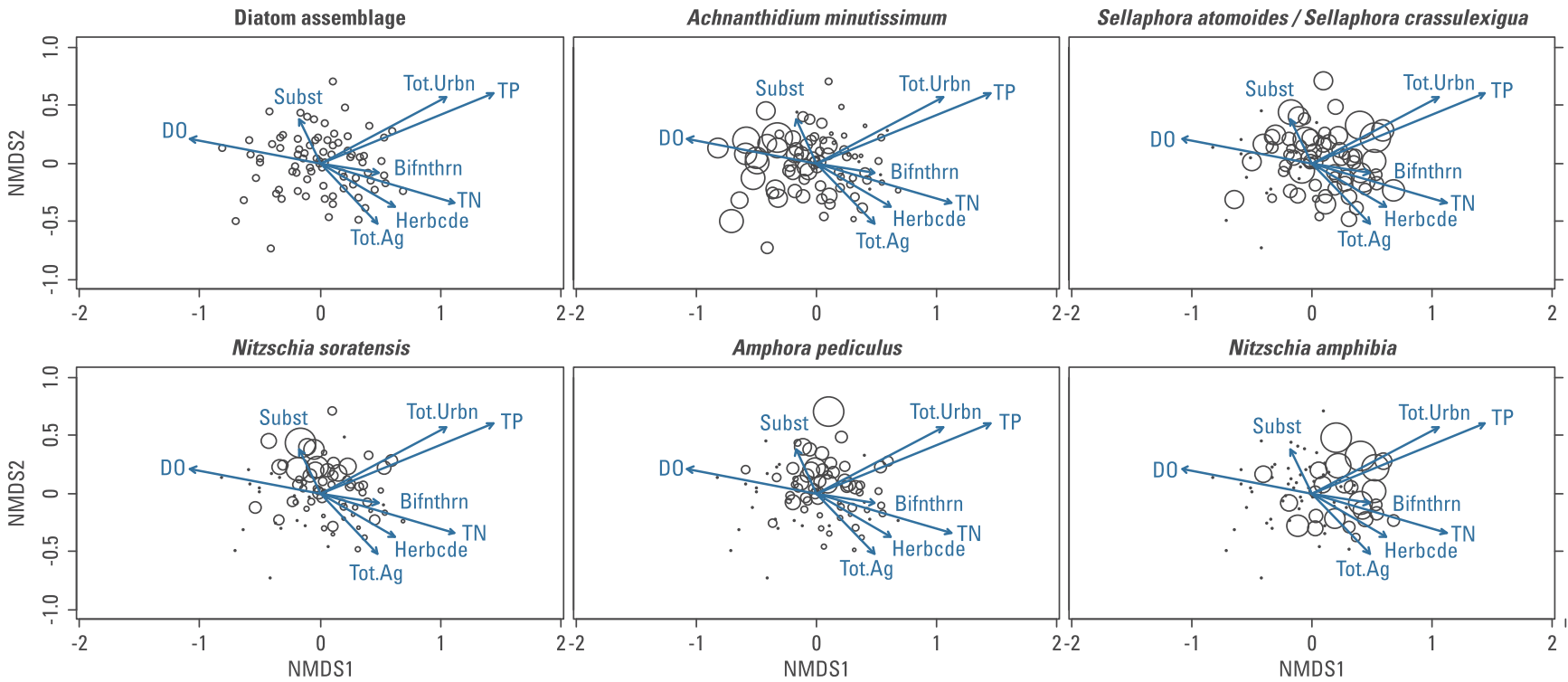

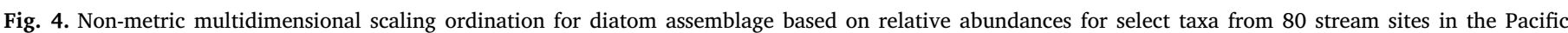

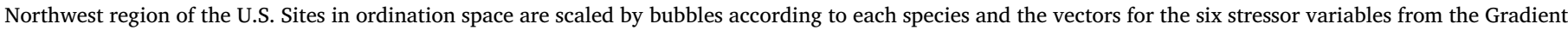
Forest models plotted. For variable definitions and units, see Supplemental File, Table S2.

values.

As a comparison to the GF species models and to explore the relationship between assemblage and environmental stressors, we present ordination plots for select taxa scaled by that taxon's relative abundance and plotted with the vectors of the final stressor variables in the GF model, we also add vectors for total urban and agricultural as indicators of land use disturbance gradients (Fig. 4). The diatom ordination plots and vectors show an urban and nutrient gradient along NMDS axis 1 with high urban land use and high TP increasing with positive values of axis 1 . Another gradient is evident along axis 2 representing increased substrate size and lower agriculture with positive values of NMDS axis 2. These lower agriculture land use sites also have lower TN, herbicides, and bifenthrin, larger substrate and higher DO than sites with higher urban and agriculture. The ordination plots correspond with the GF diatom cumulative species plots and directional response provided in Table 1. For example, A. minutissimum had higher abundances (larger bubbles) in the area with higher values for DO and substrate and lower abundances for the higher values for nutrients, contaminants, and urban and agricultural land use (Fig. 4), while $N$. amphibia shows the opposite pattern; they both follow the general response shown in the GF models. On the other hand, some of the other taxa shown in the ordination plots have positive responses to nutrients and negative responses to the contaminants and agriculture but positive to urban gradient (e.g., N. soratensis and Amphora pediculus).

\subsection{Invertebrates}

There were 255 total invertebrate taxa and 90 taxa remaining after rare taxa were removed. Baetis tricaudatus (Ephemeroptera mayfly) was the most common taxon occurring at 74 out of 82 sites. There were six other taxa that occurred at more than 63 sites, all of which were Dipterans (Brillia, Tvetenia, Micropsectra, Simulium, Eukiefferiella, and Polypedilum). There were 47 invertebrate taxa with positive GF models and 20 taxa with $\mathrm{R}^{2}$ values $>0.18$ (Table 1), while only Brillia and Tvetenia of the common Dipterans had a positive model. There were nine stressor variables kept in the GF invertebrate models, temperature was the top variable (Table 1 and Fig. 5). The PEC four contaminant stressor variable (PEC.LEB), bifenthrin in sediment, substrate size and $\mathrm{TP}$ concentration all showed almost immediate responses by the invertebrate taxa (Fig. 5), while the response range for maximum minimum (minmax) temperature (maximum of the minimum temperatures over the 42 days prior to ecological sampling) was between 16 and $18{ }^{\circ} \mathrm{C}$, and 7-8 mg/L for DO minimum. Many of the EPT (mostly sensitive taxa in the orders Ephemeroptera, Plecoptera and Trichoptera) taxa showed negative responses to nutrients, temperature and contaminants, and positive response to substrate size (e.g., Epeorus, Zapada, and Wormaldia) (Table 1 and Fig. 6). The exception was the tolerant Trichopteran Cheumatopysche, which showed positive responses to nutrients, temperature and number of pesticides detected in water. Most of the significant models for Dipterans (e.g., Brillia, Tvetenia, and Dicranota) also showed negative responses to contaminants similar to the sensitive EPT taxa. On the other hand, the two snail taxa (Juga and Fluminicola) showed relatively tolerant responses with positive repsonse to nutrients, temperature, and contaminants.

The invertebrate ordination plots and vectors showed similar patterns to those in the diatom-based ordinations, with a bit more separation of the higher agriculture and urban sites (Fig. 7). The bubble plots correspond with the patterns observed in the GF models. Epeorus (Ephemeroptera mayfly) and Zapada (Plecoptera stonefly) relative abundances were positively correlated with DO, substrate size, low contaminants, and low urban and negatively correlated with contaminants, nutrients, temperature, high urban and agriculture. The relative abundance of Brillia was positively correlated with DO and substrate size; however, Brillia was also positively correlated with TN and urbanization. Cheumatopysche and Juga have a well-known tolerance to stressors (Barbour et al., 1999, Waite et al., 2019), and in the ordination plots and the GF models in this study were positively correlated with temperature, nutrients and contaminants, while the opposite pattern can be observed in the sensitive EPT taxa (Epeorus, Glossosoma, Zapada, Drunella, Hesperoperla, and others, Table 1).

\subsection{Fish}

The Pacific Northwest is known for having a low diversity of fish species. We collected a total of 33 species, 10 of which were non-native taxa. Cutthroat trout (Oncorhynchus clarki) was the most common species and occurred at 66 of the 82 sites sampled. Only four other taxa occurred at 40 or more sites (reticulate sculpin Cottus perplexus, coho salmon Oncorhynchus kisutch, lamprey Petromyzontidae, and torrent sculpin Cottus rhotheus), all native taxa. Since there were fewer fish taxa than diatoms or invertebrates, we only removed rare fish taxa that occurred at less than five sites for a total of 18 fish taxa included for 

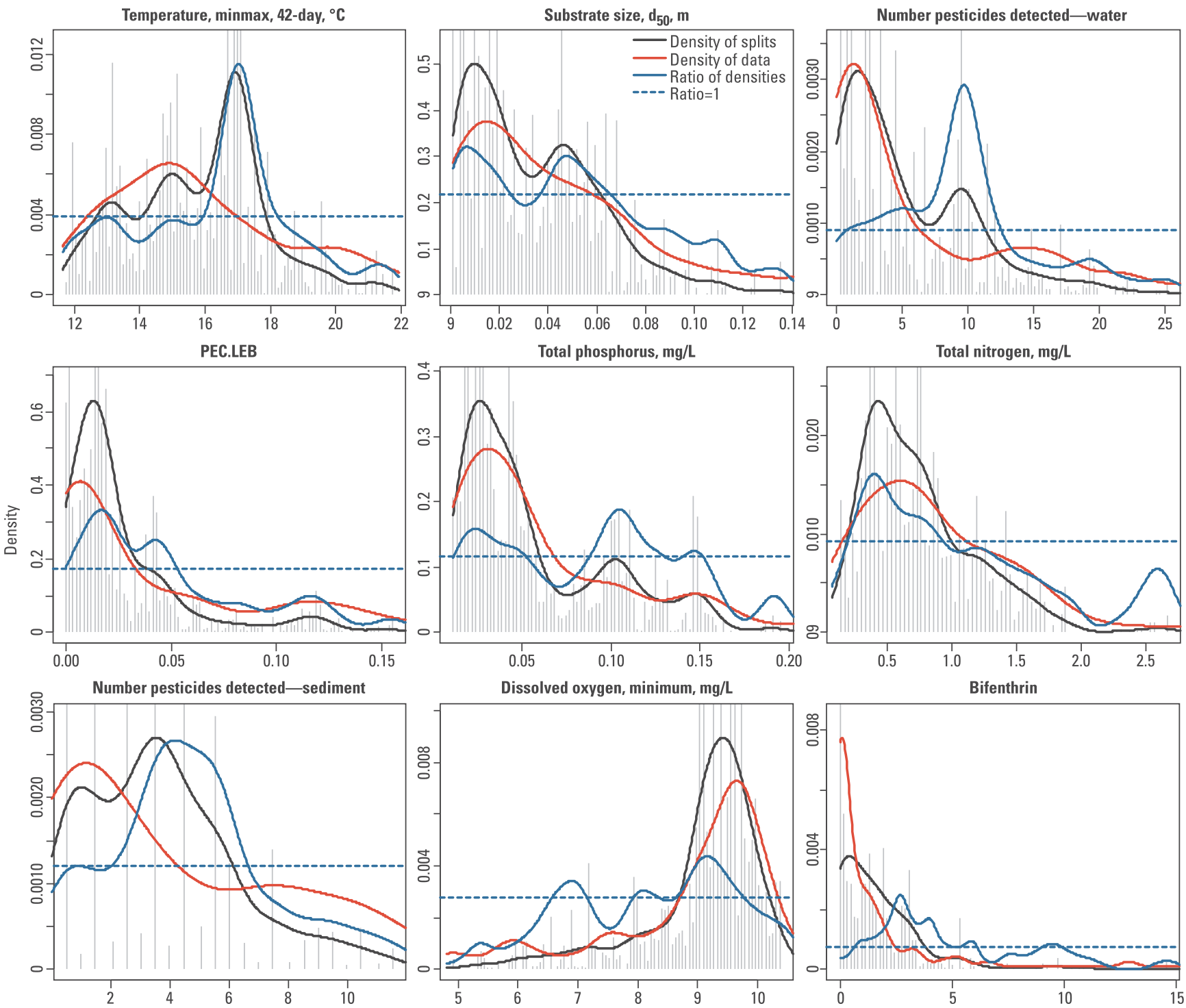

Fig. 5. Split density plots for invertebrate assemblages from gradient forest models from streams in the Pacific Northwest regional study ( $\mathrm{n}=82$ ). Split density showing the raw split importance computed from split point density weighted by importance (black line), the binned raw split importance density (narrow gray bars), the density function of the observed predictor values (red line), and the estimated importance function or compositional turnover rate (blue line) is computed as the ratio of split and data density (black/red lines). The raw importances are normalized so that the area under the blue curve is equal to the $\mathrm{R}^{2}$ for all species for that environmental variable (Ellis et al. 2012). Ratios > 1 (dashed horizontal line) of the importance function indicate that compositional rate of change is relatively larger in that stressor range than elsewhere in the stressor gradient. Thresholds are visually identified in those areas where the blue line is above the dashed line, yet considering the full range of the stressor. For variable definitions and units, see Supplemental File, Table S2.

model development. There were 12 fish taxa with positive GF models and seven taxa with $\mathrm{R}^{2}>0.18$ (Table 1 ). There were also nine stressor variables kept in the final fish GF models, five of them were the same or slight variations of the variables included in the invertebrate models (DO minimum, substrate, temperature, PEC sediment contaminants, and number of pesticides detected in sediment). The top stressor identified in the GF fish models was temperature (Figs. 8-10 and Table 1), three taxa had a strong positive response to maximum temperature, while only one taxon had a negative response (Table 1). Overall, fish taxa response to maximum temperature began around $18{ }^{\circ} \mathrm{C}$, around 100 days for flow peak interval and greater than two pesticides detected in sediment (Fig. 8). Similar to the response observed in the diatom and invertebrates GF models, there appears to be an almost immediate response by fish taxa for substrate size $\left(d_{50}\right.$ and soft sediment depth) and the two contaminant variables (PEC in sediment and pyrethroid/phenylpyrazine insecticides - predominantly fipronil and its degradates). Fish taxa response began at DO minimum values near $6.5 \mathrm{mg} / \mathrm{L}$ and when maximum depth change was greater than about $0.05 \mathrm{~m}$.

The two salmonids (cutthroat trout and coho salmon) and redside shiner showed dramatic responses to maximum temperature around 19-20 ${ }^{\circ} \mathrm{C}$ (Fig. 9); however, the response direction was negative for the salmonids and positive for redside shiner (Table 1). About half of the fish taxa appear to respond to flow peak intervals beginning around 50 days yet with a more gradual increase, while fish taxa begin to respond to both substrate measures almost immediately. Cutthroat trout began responding to DO minimum values above 6.5 and coastrange sculpin above $9.5 \mathrm{mg} / \mathrm{L}$ (Fig. 9), yet they both seem to respond to number of pesticides in sediment at about the same value $(>2)$. On the other hand, torrent sculpin seemed to be the only taxon that responded significantly to the PEC aggregate sediment contaminant measure (PEC.LEB; negative response Table 1, Fig. 9).

The ordination plots and vectors for the common fish taxa show similar response patterns as those shown in the diatom and invertebrate 

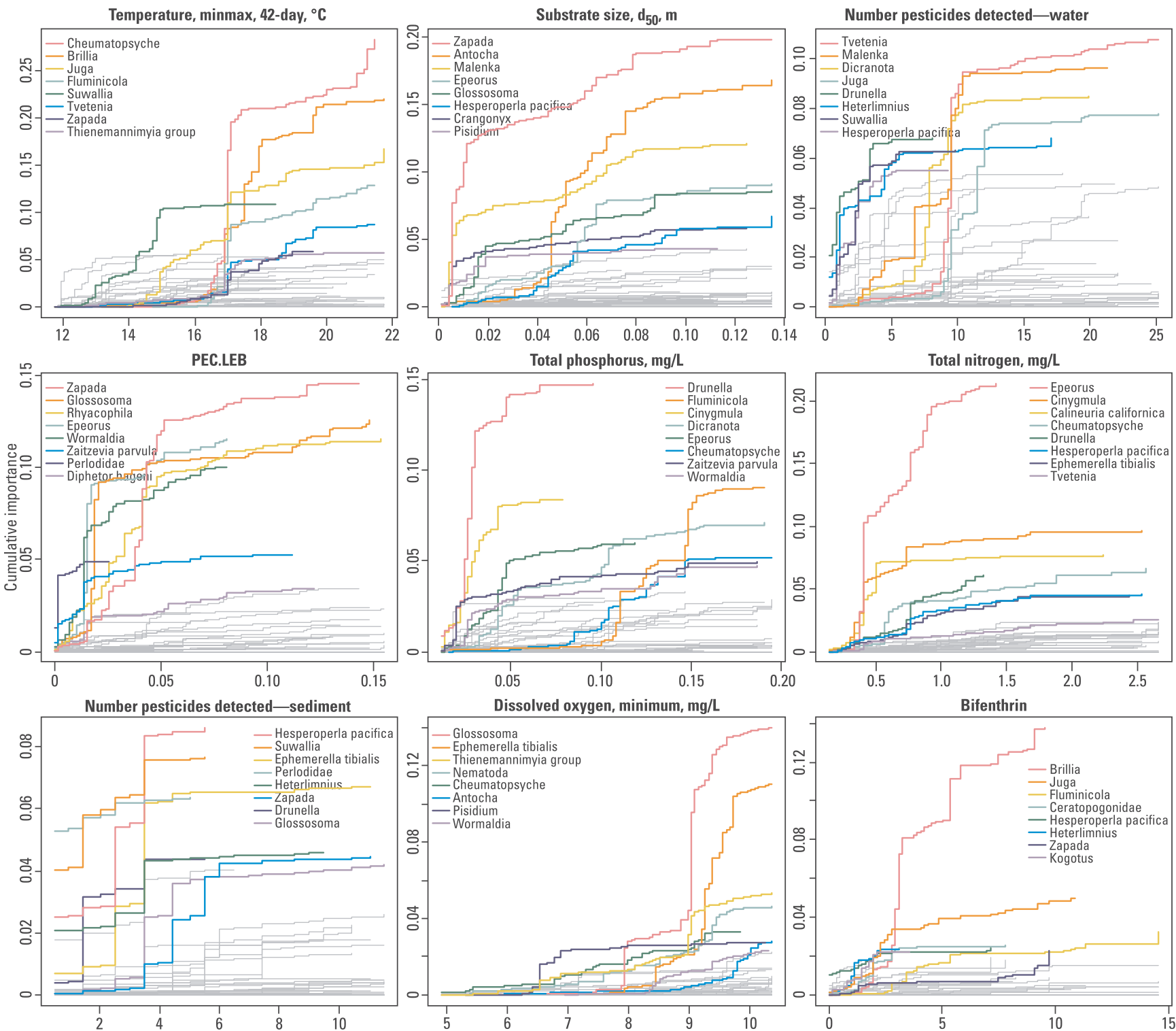

Fig. 6. Cumulative split importance curves for invertebrate taxa scaled by their respective $R^{2}$ from gradient forest models from streams in the Pacific Northwest regional study $(n=82)$. Only the top eight most important taxa are labeled. Note: these are cumulative plots, the directionality of the taxa responses cannot be seen in these plots, see Table 1 for response direction. For variable definitions and units, see Supplemental File, Table S2.

plots, yet with more spread in the fish sites along the first axis than in the diatom and invertebrate plots (Fig. 10). Cutthroat trout and coho salmon abundances were positively correlated with DO minimum and substrate size and negatively correlated with temperature, contaminants, maximum depth change, and urban or agricultural land use (Fig. 10). An opposite pattern was observed for reticulate sculpin and redside shiner, which were positively correlated with increasing temperature, contaminants, depth change, and urban or agriculture and negatively correlated with DO and substrate size. Torrent sculpin were positively correlated with DO, flow peak intervals and negatively correlated with the PEC.LEB sediment aggregate measure, contaminants, depth change, and urban land use are low (Fig. 10).

\section{Discussion}

\subsection{Diatom assemblage response to stressors}

The gradient forest models allowed us to evaluate a complex mix of stressors and taxa to gain insight into the responses of diatoms to instream stressors. Nutrients (TP and TN) were the most important explanatory variables for the GF models based on the individual diatom taxa. These findings confirm the known tolerances of diatom taxa and also provide specific information about potential thresholds related to urban stressors. For example, the response thresholds shown for TN and TP observed in the significant GF models were similar to what has been reported elsewhere (ca. 0.02 for TP and $0.5 \mathrm{mg} / \mathrm{L}$ for TN, Stevenson et al., 2006, Potapova and Charles, 2007, Waite, 2014, Munn et al., 2018). The GF models also allowed us to evaluate the varied response of individual diatom taxa to nutrients. For example, Achnanthidium minutissimum and A. rivulare responded negatively to TP at concentrations at or below $0.02 \mathrm{mg} / \mathrm{L}$, while Nitzschia soratensis responded positively at about the same concentration. Some taxa respond at much higher nutrient concentrations, for example, Platessa bahlsii and Nitzschia spp. don't appear to respond until ca. $0.09 \mathrm{TP}$. We observed a similar pattern for individual taxa responses to TN; many taxa respond at ca. $0.5 \mathrm{mg} / \mathrm{L}$ TN, while some don't respond much until concentrations are above $1.5 \mathrm{mg} / \mathrm{L}$.

Our results were largely consistent with the findings from a national study. Potapova and Charles (2012) used a dataset of 1240 river sites throughout the continental U.S. to assess the relationships between 

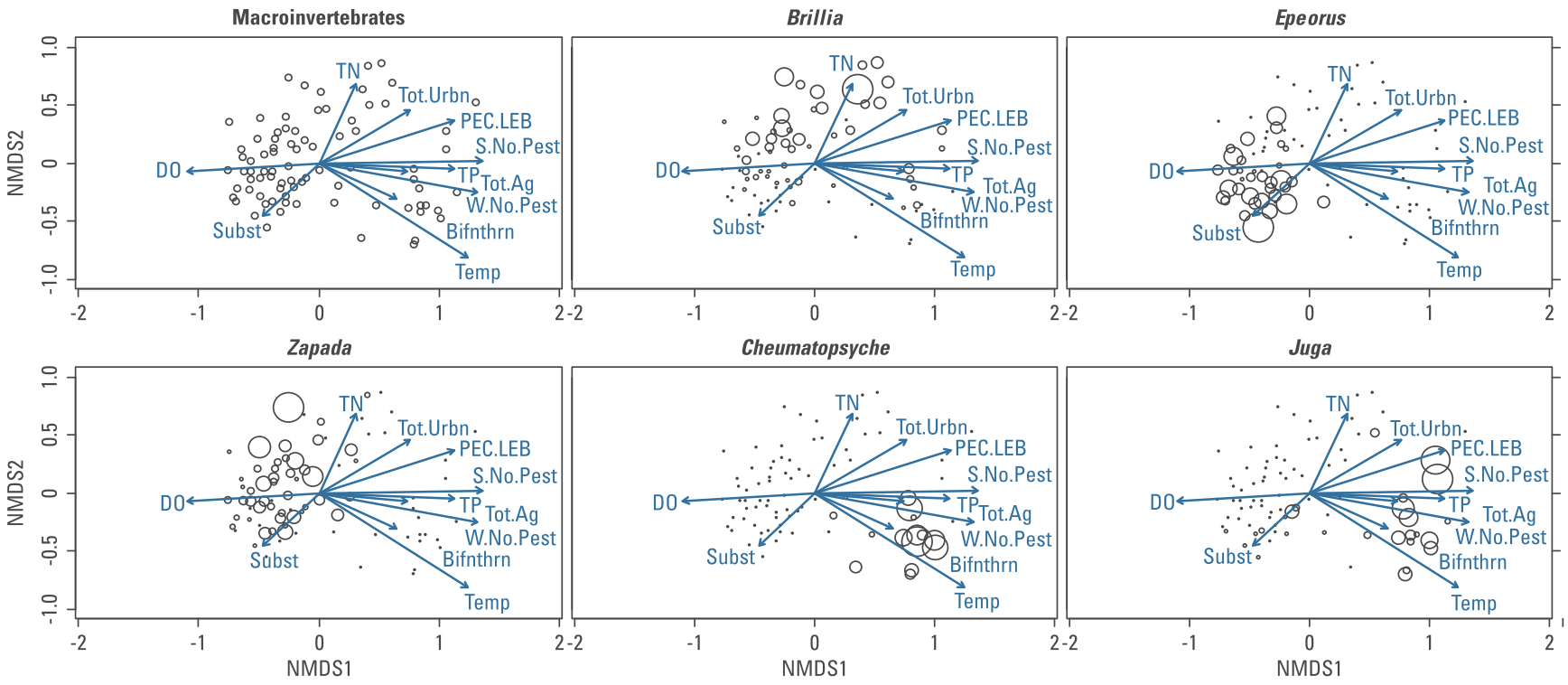

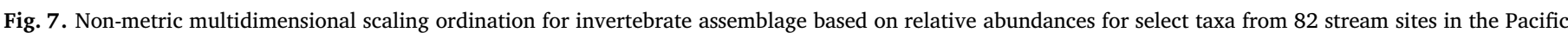

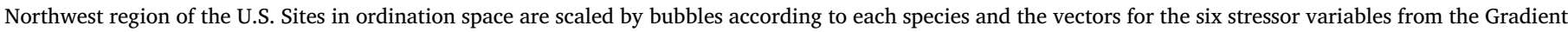
Forest models plotted. For variable definitions and units, see Supplemental File, Table S2.

diatom taxa and nutrient conditions. They classified A. minutissimum and $A$. rivulare, two adnate taxa, as low phosphorus and nitrogen species. In this study, A. rivulare was, however, positively responding to TN and Ponader and Potapova (2007) reported that $A$. rivulare was widely distributed including sites with elevated nutrient concentrations in Appalachian streams. In general, many of the nutrient tolerant taxa are motile Nitzschia and Naviculoid taxa. Kelly et al. (2007) noticed both nutrient tolerant taxa and motile taxa increased along a trophic gradient and Pillsbury et al. (2019) developed indicator species analysis for 135 diatom taxa and Nitzschia and Navicula taxa consistently had high indicator values for high TN and TP.

GF models identified bifenthrin in sediment and herbicide in water as the most important contaminants for diatoms, which showed a range response. Some diatoms such as A. minutissimum and Planothidium lanceolatum, showed an almost immediate response as contaminant concentration increased. However, Melosira varians and Navicula germainii showed a delayed response and then many taxa that showed no response. Adverse effects of herbicides on algal growth have been well documented in laboratory ecotoxicity studies, with single species or natural assemblages (Rimet and Bouchez, 2011, Roubeix et al., 2011, Wood et al., 2017). At the assemblage level, species responses to herbicides may vary substantially (Debenest et al., 2009). Debenest et al. (2009) reported that tolerant diatom species abundances were not significantly affected by the herbicides isoproturon or s-metolachlor while abundance of facultative diatom taxa significantly increased at $30 \mu \mathrm{g} / \mathrm{L}$ isoproturon compared to the control with no herbicide addition. Facultative diatom taxa can switch from autotrophic to facultative mode. Our results show that several diatom taxa, particularly these nutrient tolerant taxa, showed positive responses to herbicides while two adnate taxa (A. minutissimum, P. lanceolatum) showed the opposite. In field studies of diatoms, it is difficult to discern the effect of herbicides from other stressors. Several studies indicated that the effects of herbicides were not detectable in rivers with elevated nutrient conditions resulting from agricultural runoff (Berard et al., 1998, Andrus et al., 2015). In addition, some diatom assemblages have been shown to recover from herbicide exposure (e.g., atrazine) within $48 \mathrm{~h}$ (Prosser et al., 2015). Furthermore, prior exposure history can also affect diatoms' responses to herbicide exposure (Wood et al., 2017).

\subsection{Invertebrate assemblage response to stressors}

GF models showed that temperature, substrate, and pesticides had the strongest association with invertebrates. Temperature was the top variable in the GF models and there were nine taxa that had a relatively strong response (Table 1), with six negative and three positive taxon responses to temperature. The observed relationships were similar to patterns expected of sensitive cool-water and warm-water taxa. Some taxa showed responses starting around $13-14{ }^{\circ} \mathrm{C}$ (Juga and Suwallia), while a number of other taxa responded around $17{ }^{\circ} \mathrm{C}$ (positive response: Cheumatopysche, Fluminicola, Tvetenia; negative response: Brilla and Zapada). This finding is supported by Huff et al. (2006), who determined the optima for temperature and fine substrate for invertebrate taxa collected across the state of Oregon and found the optima for Cheumatopysche to be $24^{\circ} \mathrm{C}$ and 20 percent fine substrate, both some of the highest optima across the state.

Substrate size was the next most important variable in the GF models and there were eight invertebrate taxa that showed a relatively strong response, seven of which were positively associated with substrate size. This finding suggests that as substrate sizes increase from small silts and fines to larger gravels and cobbles, there is a positive response by invertebrates (Fig. 6). Substrate size is a well-known important determinant of invertebrate abundance and diversity, with highest diversity in the mid-size ranges (large gravels to cobbles) and the lowest abundance and diversity near the two extremes, sand and bedrock (Minshall, 1984; Munn et al., 2009; Relyea, et al., 2012; Edwards, 2014; Waite, 2014; Hubler et al., 2016).

The number of pesticides detected in water samples was the third strongest explanatory variable and there were three other sedimentbased contaminant variables among the nine stressor variables selected in the invertebrate GF models. Invertebrates showed a negative response to pesticides at very low concentrations and sensitive EPT taxa were frequently among the top eight taxa listed in the GF cumulative plots. The one exception to this was bifenthrin, which only a few taxa responded and the strongest response, the dipteran Brillia, showed a stair-step pattern as concentration increased from 3 to $10 \mu \mathrm{g} / \mathrm{kg}$ (negative response, Table 1 ).

Nutrients (TN and TP) were also important stressor variables in the invertebrate GF models. Four taxa had strong responses for both nutrients and seven others responded to only one of the nutrient variables. Nine taxa had negative responses to one or both nutrients and three had 

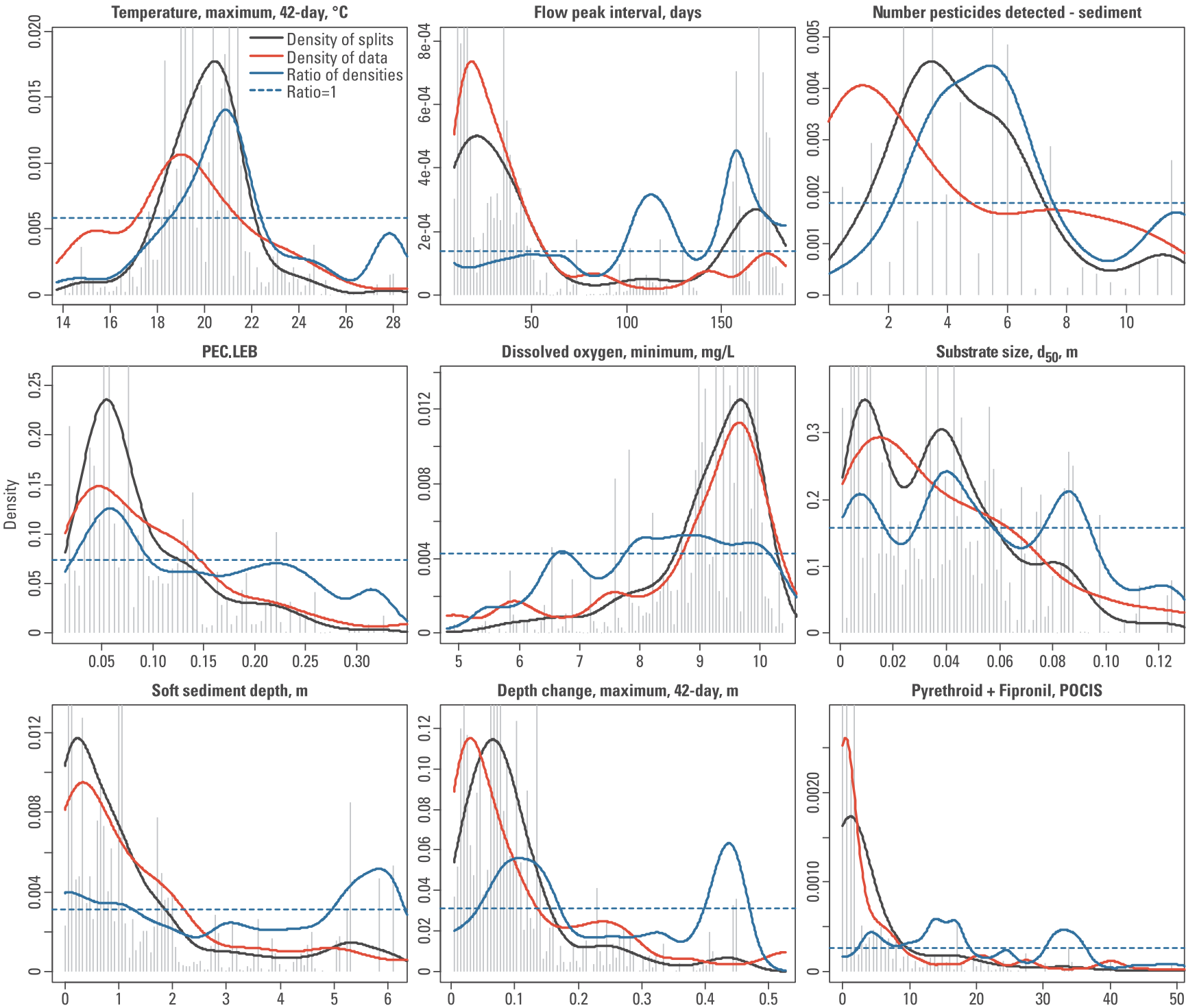

Fig. 8. Split density plots for fish assemblages from gradient forest models from streams in the Pacific Northwest regional study (n $=82)$. Split density showing the raw split importance computed from split point density weighted by importance (black line), the binned raw split importance density (narrow gray bars), the density function of the observed predictor values (red line), and the estimated importance function or compositional turnover rate (blue line) is computed as the ratio of split and data density (black/red lines). The raw importances are normalized so that the area under the blue curve is equal to the $\mathrm{R}^{2}$ for all species for that environmental variable (Ellis et al. 2012). Ratios > 1 (dashed horizontal line) of the importance function indicate that compositional rate of change is relatively larger in that stressor range than elsewhere in the stressor gradient. Thresholds are visually identified in those areas where the blue line is above the dashed line, yet considering the full range of the stressor. For variable definitions and units, see Supplemental File, Table S2.

positive responses. Many of the sensitive EPT taxa had a negative response to nutrients, particularly the insects that gather their food by scraping algae from rocks (i.e., grazers). While it is well known that nutrients increase algae growth and thus provide more food for invertebrate grazers, we interpret the negative response to nutrients as a general indicator of high-quality oligotrophic streams like those typically found in forested watersheds of the PNW to which native taxa are evolved. DO had a strong response for only two taxa (Table 1), yet they show an obvious "threshold" type response with little or no abundances until minimum DO goes above $8-9 \mathrm{mg} / \mathrm{L}$ (Fig. 6). The two taxa with a strong response to DO are sensitive EPT taxa, Glossosoma sp. and Ephemerella tibialis, both are grazers and generally found in streams in good condition in the PNW.

\subsection{Fish assemblage response to stressors}

Temperature (maximum) was the most important variable selected in the GF models for fish. In general, fish taxa respond once maximum temperatures go above $18{ }^{\circ} \mathrm{C}$ (Fig. 8), while the individual species plots show the salmonids (coho and cutthroat) begin responding (negative) near $17{ }^{\circ} \mathrm{C}$ and redside shiner and reticulate sculpin at ca. $20{ }^{\circ} \mathrm{C}$ (positive) with a second peak for reticulate sculpin at $28{ }^{\circ} \mathrm{C}$ (reticulate sculpin are known as a tolerant taxon). Salmonids are known for requiring cool water streams, and as a result, the state of Oregon has their temperature standard set at $18{ }^{\circ} \mathrm{C}$ for salmonid bearing streams based on a 7-day moving average for the rearing and migration periods, approximately spring through early fall (Oregon Department of Environmental Quality, 2019).

Unlike the diatom and invertebrate models, the GF models for fish selected a flow alteration variable, with three fish taxa showing a positive response and one a negative response to time since last peak flow (90th percentile of stage; see SI Table 2). Several fish taxa showed a gradual change as the interval since last peak flow increases, while rainbow trout showed a dramatic increase as flow peak interval 

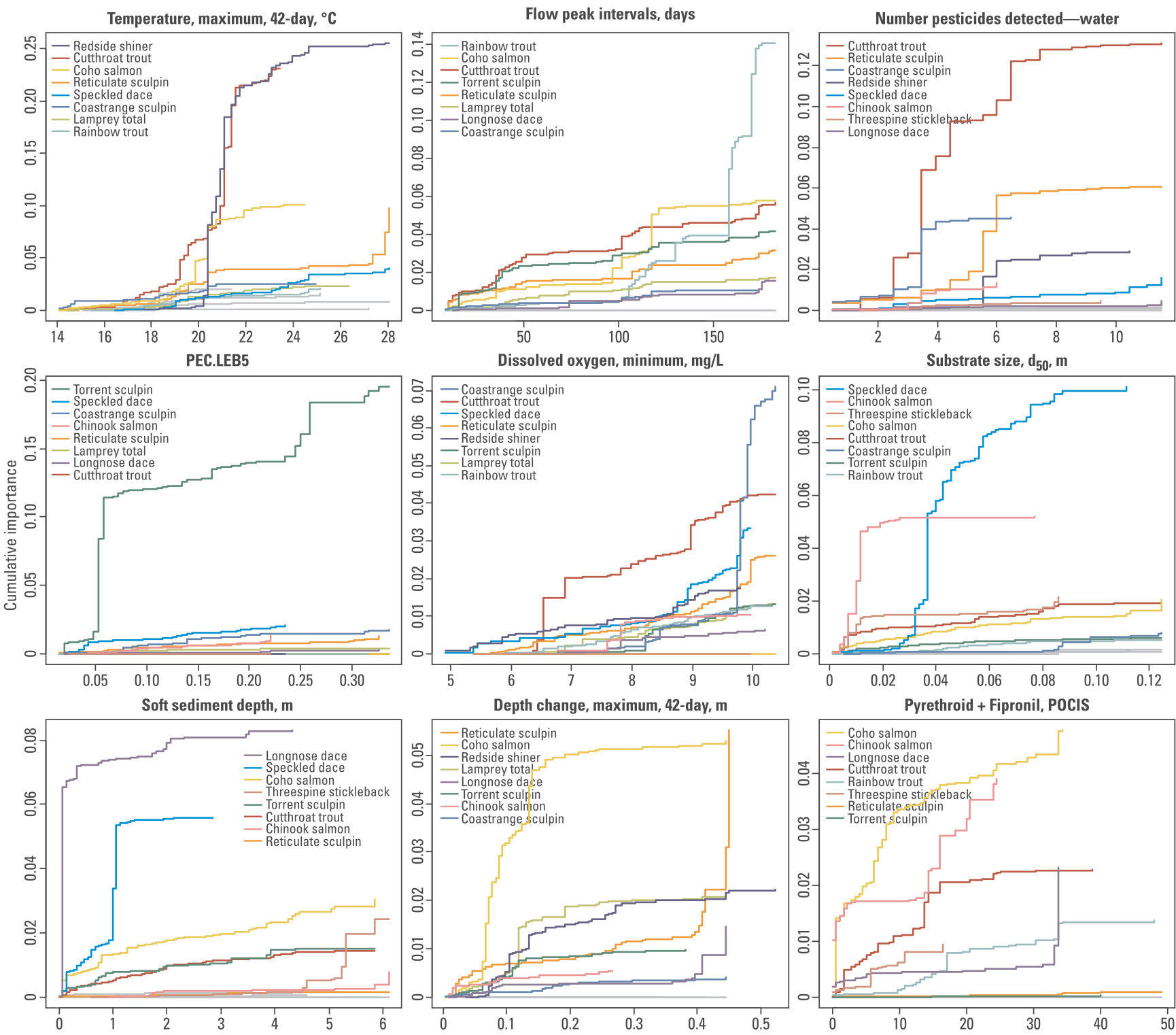

Fig. 9. Cumulative split importance curves for fish taxa scaled by their respective $\mathrm{R}^{2}$ from gradient forest models from streams in the Pacific Northwest regional study $(n=82)$. Only the top eight most important taxa are labeled. Note: these are cumulative plots, the directionality of the taxa responses cannot be seen in these plots, see Table 1 for response direction. For variable definitions and units, see Supplemental File, Table S2.

increased beyond 100 days. For reasons we cannot explain, cutthroat trout had a negative response with flow peak interval, decreasing as the time goes above 100 days. It is possible that the flow peak interval variable is correlated to other factors affecting the habitat for cutthroat trout that we did not measure. There were four sediment-related variables selected in the fish models, two related to substrate size (substrate $\mathrm{d}_{84}$ and soft sediment depth) and two related to sediment contaminants (number of pesticides detected in sediment and PEC.LEB contaminant aggregate). Cutthroat trout seemed to respond negatively almost immediately as the number of pesticides detected increased, while redside shiner and reticulate sculpin did not respond positively until above four pesticides. On the other hand, torrent sculpin was the only taxon that had a strong negative response to the sediment contaminant aggregate (PEC.LEB). Cutthroat trout and speckled dace respond positively to substrate size and longnose dace, speckled dace and coho salmon all respond negatively to depth of soft sediment (i.e. accumulation of fine substrate).

Overall, the various fish species respond to both sediment contaminants and sediment size variables as we would expect since these are all native species for western U.S. and generally sensitive indicator taxa (cutthroat, coho and longnose) or intermediate indicators (speckled dace). However, there were only two fish species that showed a strong association to sediment size (substrate size and soft sediment depth); this might be due partly to the natural low diversity of fish in PNW and/or the relatively low sample size for each taxon. Only three fish species occurred at more than 55 sites and the rest of the fish that had significant GF models ranged from 5 to 44 sites. This resulted in low statistical power for many of the fish GF models, especially considering that many contaminants have non-zero values at almost half of the sites. The concentration of pyrethroid insecticide in water was another contaminant selected in the models, and coho salmon showed an immediate strong negative response as values increased above zero. Coho also showed a strong negative response to maximum depth change over the 42 days prior to ecological sampling, while reticulate sculpin showed a positive response. As expected, cutthroat showed a strong response to minimum dissolved oxygen starting at values of 6.5 and increasing to $10 \mathrm{mg} / \mathrm{L}$, the highest values measured. Speckled dace, reticulate sculpin and redside shiner, on the other hand, all seem to 

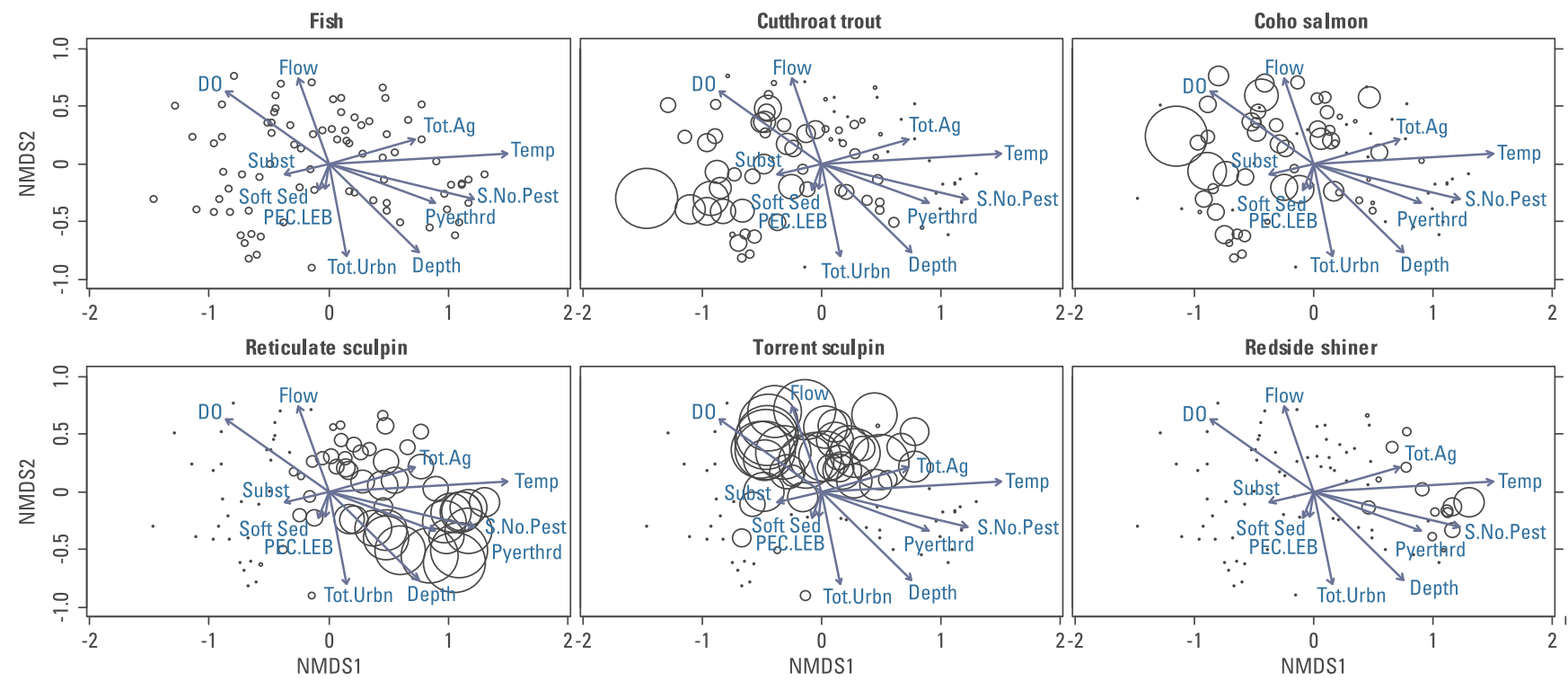

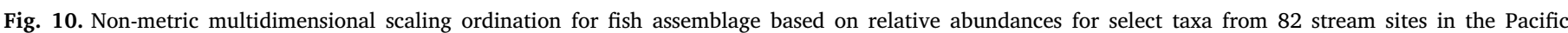

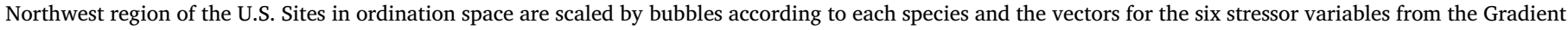
Forest models plotted. For variable definitions and units, see Supplemental File, Table S2.

have a wide tolerance range to DO, with occurrences starting at $5 \mathrm{mg} / \mathrm{L}$ but increasing through the full range of values.

\subsection{Effect of drought on multi-stressors}

This study was conducted in 2015 and occurred during a 30-year drought for the PNW region, which usually has a temperate climate with extensive fall, winter and spring rains. However, in the spring of 2015 when water quality samples were being collected (April-May) this region was already in an unusual drought with few rain storms that generated any significant runoff into streams from the surrounding landscape. During the 2015 April-May period, stream flow was well below median daily streamflow calculated from the previous 15-20 years for both reference and highly urban sites with long term flow records (E.F. Dairy Creek and Fanno Creek, USGS gage data). The number of quick peaks in flow that signify a typical flashy urban stream were cut in half and were in general smaller in magnitude than in previous years (Oregon USGS gages). As a result, flow alteration metrics were not found to be important in either the diatom or the invertebrate GF models and only showed up as important in the fish models. This was unexpected, because urban influenced streams are known to be characterized by a high degree of flashiness that is often considered to be one of the key impacts to the ecology (Walsh et al., 2005; Waite et al., 2008; Brown et al., 2009; Cuffney et al., 2010). Waite et al. (2019) found that flow alteration metrics were important in eight of nine models (Boosted regression tree models) assessing the impact of multiple stressors in a similar urban gradient study with the same three biotic assemblages as in this study. Because of the drought we also expected that the amount of storm runoff from the surrounding landscape flowing into the sampled streams would be reduced and thus expected that the types and amounts of contaminants in the streams during our sampling period would be reduced. To our surprise, various contaminants were important in many of the GF models even though we do not believe there was much stormwater runoff into most streams that would be typical of a more normal precipitation year. The lower flows during the spring of 2015, likely meant that there was lower dilution of contaminants coming into the streams compared to a more normal precipitation year which has more stormwater runoff and possibly higher deliveries of contaminants but also more dilution. An unanswered question from this study is where are the contaminants coming from during drought periods when there are few storm- generated runoff events?

\section{Conclusions and comparisons among the three biotic assemblages}

GF model results for diatoms, invertebrates and fish showed that several environmental variables were commonly selected in all three models including substrate size, DO and two or more different contaminant measures. For example, five of the six variables in the diatom models occurred in the invertebrate models though two of the variables were based on slightly different summary measures. All the assemblages had some taxa that responded positively to increases in substrate size (e.g., sensitive native taxa) and some taxa responded negatively. These responses illustrate the critical importance of substrate size as a medium for stream biota and of the potential impacts of small increases in fine sediment to organisms evolved for relatively clean, high-gradient PNW streams (Munn et al., 2009; Edwards, 2014; Hubler et al., 2016). Dissolved oxygen is another critical factor affecting all biology in streams and the three assemblages sampled in this study all showed assemblage level response as minimum daytime DO values increased above ca. 6-6.5 mg/L, with the most sensitive taxa in each group showing strong positive response as DO rose above these levels. Contaminants were also an important stressor in the GF models. All three assemblages negatively responded when any of the contaminant measures increased above zero, except for the more tolerant taxa of each assemblage, many of which responded positively and some at relatively high values along the contaminant gradients. Many studies have shown that stream biotic assemblages are generally quite sensitive to small increases in various contaminants (water and sediment based) and the results from this study corroborate these findings (Mondy et al., 2016; Ponsati et al., 2016; Schafer et al., 2016; Moran et al., 2017; Waite et al., 2019).

Both nutrient stressors were important in both the diatom and invertebrate GF models but not for fish. TP and TN were the top two variables for diatom models and various taxa responded at different nutrient concentrations; however, many responded at low nutrient values, ca. 0.02 for TP and $0.5 \mathrm{mg} / \mathrm{L}$ for TN. These lower nutrient thresholds are in line with the general published literature (Stevenson et al., 2006; Potapova and Charles, 2007; Waite 2014; Munn et al., 2018). Though nutrients were not the top variables in the GF models for invertebrates, they responded approximately at the same nutrient 
values for both TP and TN as the algal assemblage. However, unlike the diatom taxa, the majority of invertebrate taxa responded negatively to nutrients (six for TN and five for TP), while only a small portion responded positively (one for TN and three for TP). The invertebrate taxa responses follow known tolerance assignments with the more sensitive EPT taxa responding negatively to nutrients and the more tolerant taxa positively.

The findings of this study demonstrate the value of using multiple assemblages to monitoring stressor gradients associated with urban stream systems and the importance of evaluating the responses of individual taxa to stressors. In the GF models, distinct taxa responded to multiple stressors following general patterns of known sensitive versus tolerant taxa for each of the biotic groups studied, yet the models allow the evaluation of taxon-specific thresholds.

\section{Credit authorship contribution statement}

Ian R. Waite: Conceptualization, Formal analysis, Methodology, Writing - original draft, Writing-review \& editing. Yangdong Pan: Conceptualization, Formal analysis, Methodology, Writing - original draft, Writing-review \& editing. Patrick M. Edwards: Conceptualization, Formal analysis, Methodology, Writing - original draft, Writing-review \& editing.

\section{Declaration of Competing Interest}

The authors declare that they have no known competing financial interests or personal relationships that could have appeared to influence the work reported in this paper.

\section{Acknowledgements}

This research was conducted and funded by the U.S. Geological Survey National Water Quality Program's Regional Stream Quality Assessment. We wish to thank the many USGS hydrologists, biologists, and technicians who participated in the regional sampling effort. We also owe a great deal of gratitude to Dr. Thomas Cuffney for his invertebrate expertise and for running the raw invertebrate data through the IDAS software to develop the invertebrate species matrix used in these analyses and models. We also thank Dr. Roger Haro (U. Wisconsin La Crosse) for internal review and the anonymous peer reviewers for their helpful comments. Any use of trade, product, or firm names is for descriptive purposes only and does not imply endorsement by the US Government.

\section{Appendix A. Supplementary data}

Supplementary data to this article can be found online at https:// doi.org/10.1016/j.ecolind.2019.106047.

\section{References}

Andrus, J.M., Winter, D., Scanlan, M., Sullivan, S., Bollman, W., Waggoner, J.B., Hosmer, A.J., Brain, R.A., 2015. Spatial and temporal variation of algal assemblages in six Midwest agricultural streams having varying levels of atrazine and other physicochemical attributes. Sci. Total Environ. 505, 65-89.

Barbour, M.T., Gerritsen, J., Snyder, B.D., Stribling, J.B., 1999. Rapid bioassessment protocols for use in streams and wadeable rivers: periphyton, benthic macroinvertebrates, and fish. second ed. U.S. Environmental Protection Agency, Office of Water, EPA Report 841-B-99-002, Washington, D.C.

Berard, A., Pelte, T., Menthon, E., Druart, J.C., Bourrain, X., 1998. Characterisation of phytoplankton from two limnic systems contaminated by a herbicidal photosynthetic inhibitor. The PICT method (pollution-induced community tolerance): application and significance. Ann. Limnol.-Int. J. Limnol. 34, 269-282.

Brown, L.R., Cuffney, T.F., Coles, J.F., Fitzpatrick, F., McMahon, G., Steuer, J., Bell, A.H., May, J.T., 2009. Urban streams across the USA: lessons learned from studies in 9 metropolitan areas. J. N. Am. Benthol. Soc. 28, 1051-1069.

Carlisle, D.M., Meador, M.R., Short, T.M., Tate, C.M., Gurtz, M.E., Bryant, W.L., Falcone, J.A., Woodside. M.D. 2013. Ecological health in the Nation's streams, 1993-2005. U. S. Geological Survey Circular 1391.
Coles, J.F., McMahon, G., Bell, A.H., Brown, L.R., Fitzpatrick, F.A., Scudder Eikenberry, B. C., Woodside, M.D., Cuffney, T.F., Bryant, W.L. 2012. Effects of Urban Development on Stream Ecosystems in Nine Metropolitan Study Areas Across the United States. Circular 1373. U.S. Geological Survey, Reston, Virginia.

Cuffney, T.F., Brightbill, R.A., May, J.T., Waite, I.R., 2010. Responses of benthic macroinvertebrates to environmental changes associated with urbanization in nine metropolitan areas. Ecol. Appl. 20, 1384-1401.

Dahm, V., Hering, D., Nemitz, D., Graf, W., Schmidt-Kloiber, A., Leitner, P., Melcher, A. Feld, C.K., 2013. Effects of physico-chemistry, land use and hydromorphology on three riverine organism groups: a comparative analysis with monitoring data from Germanyand Austria. Hydrobiologia 704, 389-415.

De'ath, G., 2007. Boosted trees for ecological modeling and prediction. Ecology 88, 243-251.

Debenest, T., Pinelli, E., Coste, M., Silvestre, J., Mazzella, N., Madigou, C., Delmas, F., 2009. Sensitivity of freshwater periphytic diatoms to agricultural herbicides. Aquat. Toxicol. 93, 11-17.

DellaSala, D., Orians, G., Kavanagh, M., and Sims, K., 2001, Puget lowland forest (NA0524): World Wildlife Fund, Wildfinder Terrestrial Ecoregions, accessed July 2007, at http://www.worldwildlife.org/science/wildfinder/profiles/na0524.html.

Edwards, P.M., 2014. Macroinvertebrates and Excessive Fine Sediment Conditions in Oregon Coastal Streams. PhD Dissertation. Portland State University, Portland, Oregon.

Elith, J., Leathwick, J.R., Hastie, T., 2008. A working guide to boosted regression trees. J. Anim. Ecol. 77, 802-813.

Ellis, N., Smith, S.J., Pitcher, C.R., 2012. Gradient forests: calculating importance gradients on physical predictors. Ecology 93, 156-168.

Feld, C.K., 2013. Response of three lotic assemblages to riparian and catchment-scale land use: implications for designing catchment monitoring programmes. Freshw. Biol. 58, 715-729.

Fitzpatrick, F.A., Waite, I.R., D’Arconte, P.J., Meador, M.R., Maupin, M.A., Gurtz, M.E. 1998, Revised methods for characterizing stream habitat in the National WaterQuality Assessment Program: U.S. Geological Survey Water-Resources Investigations Report 98-4052, 67 p.

Gieswein, A., Hering, D., Feld, C.K., 2017. Additive effects prevail: the response of biota to multiple stressors in an intensively monitored watershed. Sci. Total Environ. 593-594, 27-35.

Graeber, D., Jensen, T.M., Rasmussen, J.J., Riis, T., Wiberg-Larsen, P., Baattrup-Pedersen, A., 2017. Multiple stress response of lowland stream benthic macroinvertebrates depends on habitat type. Sci. Total Environ. 599-600, 1517-1523.

Hambrook, J.A., Canova, M.G., 2007. Algal biomass indicators (ver. 1.0): U.S. Geological Survey Techniques of Water-Resources Investigations, book 9, chap. A7, section 7.4, accessed December 2, 2016, at https://pubs.water.usgs.gov/twri9A6/.

Hubler, S., Huff, D.D., Edwards, P., Pan, Y., 2016. The biological sediment tolerance index: assessing fine sediments using macroinvertebrates. Ecol. Ind. 67, 132-145.

Huff, D.D., Hubler, S.L., Pan, Y., Drake, D. 2006. Detecting shifts in macroinvertebrate assemblage requirements: implicating causes of impairment in streams. Oregon Department of Environmental Quality, Laboratory and Environmental Assessment Division, Watershed Assessment Section, 3150 NW 229th, Suite 150, Hillsboro, Oregon 97124 U.S.A.

Kelly, M.G., Juggins, S., Bennion, H., Burgess, A., Yallop, M.L., Hirst, H., King, L., Jamieson, B.J., Guthrie, R., Rippey, B., 2007. Use of Diatoms for Evaluating Ecological Status in UK Freshwaters. Science Report: SC030103/SR2. Environment Agency, Bristol.

Kuzmanovic, M., Lopez-Doval, J.C., De Castro-Catala, N., Guasch, H., Petrovic, M., Munoz, I., Ginebreda, A., Barcelo, D., 2016. Ecotoxicological risk assessment of chemical pollution in four Iberian river basins and its relationship with the aquatic macroinvertebrate community status. Sci. Total Environ. 540, 324-333.

Legendre, P., Legendre, L., 1998. Numerical Ecology, second ed. Elsevier, Amsterdam, The Netherlands, pp. 1998.

Mahler, B.J., Van Metre, P.C., Burley, T.E., Loftin, K.A., Meyer, M.T., Nowell, L.H., 2017. Similarities and differences in occurrence and temporal fluctuations in glyphosate and atrazine in small Midwestern streams (USA) during the 2013 growing season. Sci. Total Environ. 579, 149-158. https://doi.org/10.1016/j.scitotenv.2016.10.236.

McCune, B., Grace, J.B., 2002. Analysis of Ecological Communities. MJM Publishers, Gleneden Beach, OR.

Minshall, G.W., 1984. Aquatic insect-substratum relationships. In: Resh, Rosenberg (Ed.), The Ecology of Aquatic Insects. Praeger Publishers, New York.

Mondy, C.P., Munoz, I., Doledec, S., 2016. Life-history strategies constrain invertebrate community tolerance to multiple stressors: a case study in the Ebro basin. Sci. Total Environ. 572, 196-206.

Moran, P.W., Nowell, L.H., Kemble, N.E., Mahler, B.J., Waite, I.R., Van Metre, P.C., 2017 Influence of sediment chemistry and sediment toxicity on macroinvertebrate communities across 99 wadable streams of the Midwestern USA. Sci. Total Environ. 600, 1469-1478.

Moulton, S.R., II, Kennen, J.G., Goldstein, R.M., Hambrook, J.A., 2002. Revised protocols for sampling algal, invertebrate, and fish communities as part of the National WaterQuality Assessment Program: U.S. Geological Survey Open-File Report 02-150, 75 p., accessed April 3, 2015, at https://pubs.usgs.gov/of/2002/ofr-02-150/.

Munn, M.D., Waite, I.R., Larsen, D.P., Herlihy, A.T., 2009. The relative influence of geographic location and reach-scale habitat on benthic invertebrate assemblages in six ecoregions. Environ. Monit. Assess. 154, 1-14. https://doi.org/10.1007/s10661008-0372-9.

Munn, M.D., Waite, I.R., Konrad, C.P., 2018. Assessing the influence of multiple stressors on stream diatom metrics in the upper Midwest, USA. Ecol. Indic. 85, 1239-1248. https://doi.org/10.1016/j.ecolind.2017.09.005.

National Climatic Data Center, 2010, Climatography of the United States no. 
20-1981-2010 Normals: National Climatic Data Center database, accessed November 18, 2014, at https://www.ncdc.noaa.gov/data-access/land-based-stationdata/land-based-datasets/climate-normals/1981-2010-normals-data.

Nowell, L., Moran, P., Gilliom, R., Calhoun, D., Ingersoll, C., Kemble, N., Kuivila, K., Phillips, P., 2013. Contaminants in stream sediments from seven United States metropolitan areas: Part I: distribution in relation to urbanization. Arch. Environ. Contamin. Toxicol. 64, 32-51.

Oksanen, J., 2011. Multivariate analysis of ecological communities in R: vegan tutorial. R package version 1.7 , pp. 11-12.

Omernik, J.M., 1995. Ecoregions-A spatial framework for environmental management. In: Davis, W.S., Simon, T.P. (Eds.), Biological assessment and criteria-tools for water resource planning and decision making. Lewis Publishers, Boca Raton, Florida, pp. 49-62.

Oregon Department of Environmental Quality, August 2019. Chapter 340, Division 41. Water quality standards: beneficial uses, policies, and criteria for Oregon. 340-0410001.

Oregon Department of Fish and Wildlife. 2006. The Oregon Conservation Strategy-Willamette Valley Ecoregion: Oregon Department of Fish and Wildlife, p. 234-235. [Also available at https://www.dfw.state.or.us/conservationstrat-egy/ read the strategy.asp].

Pillsbury, R., Stevenson, R.J., Munn, M.D., Waite, I.R., 2019. Relationships between diatom metrics based on species nutrient traits and agricultural land use. Environ. Monit. Assess. 191, 228. https://doi.org/10.1007/s10661-019-7357-8.

Pitcher, C.R., Lawton, P., Ellis, N., Smith, S.J., Incze, L.S., Wei, C.L., Greenlaw, M.E., Wolff, N.H., Sameoto, J.A., Snelgrove, P.V.R., 2012. Exploring the role of environmental variables in shaping patterns of seabed biodiversity composition in regionalscale ecosystems. J. Appl. Ecol. 49, 670-679.

Ponader, K.C., Potapova, M.G., 2007. Diatoms from the genus Achnanthidium in flowing waters of the Appalachian Mountains (North America): ecology, distribution and taxonomic notes. Limnologica 37, 227-241.

Ponsati, L., Corcoll, N., Petrovic, M., Pico, Y., Ginebreda, A., Tornes, E., Guasch, H., Barcelo, D., Sabater, S., 2016. Multiple-stressor effects on river biofilms under different hydrological conditions. Freshw. Biol. 61, 2102-2115.

Potapova, M.G., Charles, D.F., 2012. Benthic diatoms in USA rivers: distributions along spatial and environmental gradients. J. Biogeogr. 29, 167-187.

Potapova, M., Charles, D.F., 2007. Diatom metrics for monitoring eutrophication in rivers of the United States. Ecol. Indic. 7, 48-70.

Prosser, R.S., Brain, R.A., Andrus, J.M., Hosmer, A.J., Solomon, K.R., Hanson, M.L., 2015. Assessing temporal and spatial variation in sensitivity of communities of periphyton sampled from agroecosystem to, and ability to recover from, atrazine exposure. Ecotoxicol. Environ. Saf. 118, 204-216.

Puget Sound Regional Council. 2016. Puget Sound trends-Population change and net migration: Puget Sound Regional Council. [Also available at http://www.psrc.org/ assets/14735/Trend-Population-201607.pdf].

Core Team, R., 2017. R: A Language and Environment for Statistical Computing. R Foundation for Statistical Computing, Vienna, Austria https://www.R-project.org/.

Rimet, F., Bouchez, A., 2011. Use of diatom life-forms and ecological guilds to assess pesticide contamination in rivers: Lotic mesocosm approaches. Ecol. Ind. 11, 489-499.

Relyea, C.D., Minshall, G.W., Danehy, R.J., 2012. Development and validation of an aquatic fine sediment biotic index. Environ. Manage. 49, 242-252.

Roubeix, V., Mazzella, N., Schouler, L., Fauvelle, V., Morin, S., Coste, M., Delmas, F., Margoum, C., 2011. Variations of periphytic diatom sensitivity to the herbicide diuron and relation to species distribution in a contamination gradient: implications for biomonitoring. J. Environ. Monit. 13, 1768-1774.

Sandstrom, M.W., Kanagy, L.K., Anderson, C.A., Kanagy, C.J., 2015. Determination of Pesticides and Pesticide Degradates in Filtered Water by Direct Aqueous-Injection Liquid Chromatography-Tandem Mass Spectrometry: U.S. Geological Survey Techniques and Methods. https://doi.org/10.3133/tm5B11 (book 5, chap. B11, 54 p.).

Schafer, R.B., Kuhn, B., Malaj, E., Konig, A., Gergs, R., 2016. Contribution of organic toxicants to multiple stress in river ecosystems. Freshw. Biol. https://doi.org/10. $1111 /$ fwb. 12811

Schinegger, R., Palt, M., Segurado, P., Schmutz, S., 2016. Untangling the effects of multiple human stressors and their impacts on fish assemblages in European running waters. Sci. Total Environ. 573, 1079-1088.

Sheibley, R.W., Morace, J.L., Journey, C.A., Van Metre, P.C., Bell, A.H., Nakagaki, Naomi, Button, D.T., Qi, S.L., 2017. Design and methods of the Pacific Northwest Stream Quality Assessment (PNSQA), 2015: U.S. Geological Survey Open-File Report 2017 1103, 46 p., https://doi.org/10.3133/ofr20171103.

Sorenson, D.G. 2012. Puget lowland ecoregion, chap. 2 of Sleeter, B.M., Wilson, T.S., and Acevedo, W., eds., 2012, Status and trends of land change in the Western United States-1973 to 2000: U.S. Geological Survey Professional Paper 1794-A, p. 43-50. [Also available at https://pubs.usgs.gov/pp/1794/a/].

Spaulding, S.A., Lubinski, D.J., Potapova, M. 2010. Diatoms of the United States: Boulder, University of Colorado Web site, http://westerndiatoms.colorado.edu.

Stevenson, R.J., Rier, S.T., Riseng, C.M., Schultz, R.E., Wiley, M.J., 2006. Comparing effects of nutrients on algal biomass in streams in two regions with different disturbance regimes and with applications for developing nutrient criteria. Hydrobiologia 561-149-165.

Stehle, S., Bline, A., Bub, S., Petschick, L.L., Wolfram, J., Schulz, R., 2019. Aquatic pesticide exposure in the U.S. as a result of non-agricultural uses. Environ. Int.

Villeneuve, B., Souchon, Y., Usseglio-Polatera, P., Ferreol, M., Valette, L., 2015. Can we predict biological condition of stream ecosystems? A multi-stressor approach linking three biological indices to physico-chemistry, hydromorphology and land use. Ecol. Indic. 48, 88-98.

U.S. Census Bureau, 2010, U.S. Census. 2010. U.S Census Web site, accessed January 2017, at https://www.census.gov/prod/www/abs/decennial/index.htm.

U.S. Environmental Protection Agency. 1999. Primary distinguishing characteristics of level III ecoregions of the continental United States: U.S. Environmental Protection Agency database, accessed July 2007, at https://www.epa. gov/wed/pages/ ecoregions/level_iii.htm.

U.S. Environmental Protection Agency. 2006. Wadeable streams assessment: a collaborative survey of the Nation's streams. EPA 841-B-06-002 www.epa.gov/owow/ streamsurvey.

Wagenhoff, A., Clapcott, J.E., Lau, K.E.M., Lewis, G.D., Young, R.G., 2017. Identifying congruence in stream assemblage thresholds in response to nutrient and sediment gradients for limit setting. Ecol. Appl. 27, 469-484.

Waite, I.R., Sobieszczyk, Steven, Carpenter, K.D., Arnsberg, A.J., Johnson, H.M., Hughes, C.A., Sarantou, M.J., and Rinella, F.A., 2008. Effects of Urbanization on Stream Ecosystems in the Willamette River Basin and Surrounding Area. U.S. Geological Survey Scientific Investigations Report 2006-5101-D, Oregon and Washington, 62 p.

Waite, I.R., Munn, M.D., Moran, P.W., Konrad, C.P., Nowell, L.H., Meador, M.R., Van Metre, P.C., Carlisle, D.M., 2019. Effects of urban multi-stressors on three stream biotic assemblages. Sci. Total Environ. 660, 1472-1485.

Waite, I.R., Van Metre, P.C., 2017. Multistressor predictive models of invertebrate condition in the Corn Belt, USA. Freshw. Sci. 36, 901-914. https://doi.org/10.1086/ 694894.

Waite, I.R., 2014. Agricultural disturbance response models for invertebrate and algal metrics from streams at two spatial scales within the U.S. Hydrobiologia 726, 285-303.

Walsh, C.J., Roy, A.H., Feminella, J.W., Cottingham, P.D., Groffman, P.M., Morgan, R.P., 2005. The urban stream syndrome: current knowledge and the search for a cure. J. N. Am. Benthol. Soc. 24, 706-723.

Wilson, T.S., Sorenson, D.G., 2012. Willamette Valley ecoregion, chap. 3 of Sleeter, B.M., Wilson, T.S., Acevedo, W., eds. 2012. Status and trends of land change in the Western United States-1973 to 2000: U.S. Geological Survey Professional Paper 1794-A, p. 51-57. [Also available at https://pubs.usgs.gov/pp/1794/a/].

Wood, R.J., Mitrovic, S.M., Lim, R.P., Kefford, B.J., 2017. Chronic effects of atrazine exposure and recovery in freshwater benthic diatoms from two communities with different pollution histories. Aquat. Toxicol. 109, 200-208. 